\title{
START II: Thinking One Move Ahead
}

by L.L. Gaines

Energy Systems Division,

Argonne National Laboratory, 9700 South Cass Avenue, Argonne, Illinois 60439

November 1991

Work sponsored by United States Department of Energy, Assistant Secretary for Defense Programs, Office of Arms Control and Non-Proliferation Technology Support 


\section{CONTENTS}

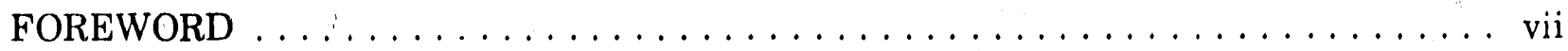

LIST OF ABBREVIATIONS AND ACRONYMS $\ldots \ldots \ldots \ldots \ldots \ldots \ldots$ viii

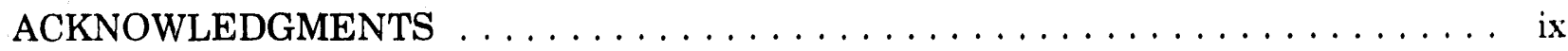

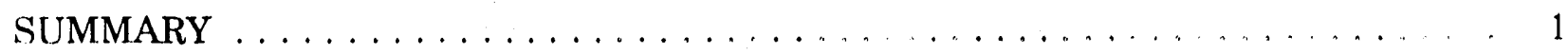

S.1 Introduction . . . . . . . . . . . . . . . . . . . . . 1

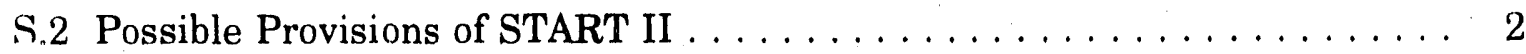

S.2.1 Provisions Based on 50\%. Reductiuns Beyond START Limits ... 2

S.2.2 Discussion ......................... 2

S.3 Resulting Force Structure $\ldots \ldots \ldots \ldots \ldots \ldots \ldots \ldots \ldots \ldots \ldots$

S.3.1 General Discussion ...................... 3

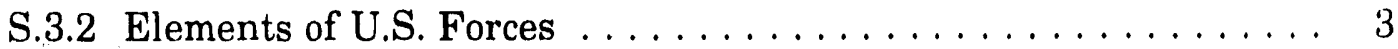

S.3.3 Possible U.S. Force Structure Scenarios . . . . . . . . . . . . . 3

S.4 Verifiability ........................... 4

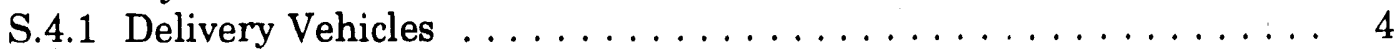

S.4.2 Nuclear Warheads $\ldots \ldots \ldots \ldots \ldots \ldots \ldots \ldots \ldots \ldots$

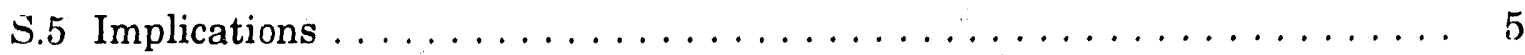

S.5.1 Need for New Weapon Systems $\ldots \ldots \ldots \ldots \ldots \ldots \ldots \ldots$

S.5.2 Utility of Possible Treaty Provisions ............... 6

S.5.3 Implications for Warhead and Fissile-Material Production . . . . . 6

S.5.4 Areas for Further Work $\ldots \ldots \ldots \ldots \ldots \ldots \ldots \ldots, 7$

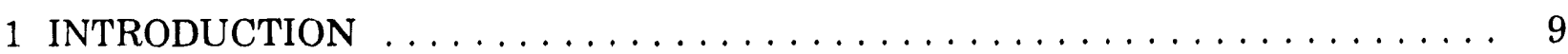

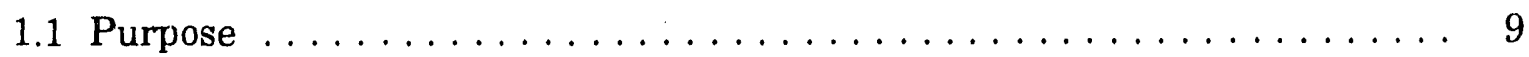

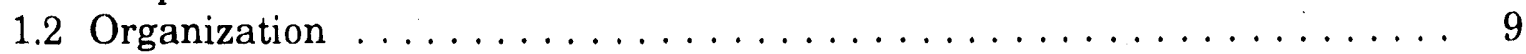

1.3 START: Status and Utility $\ldots \ldots \ldots \ldots \ldots \ldots \ldots \ldots \ldots \ldots$

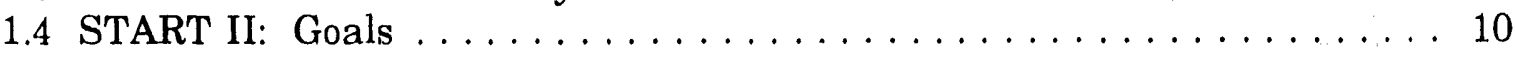

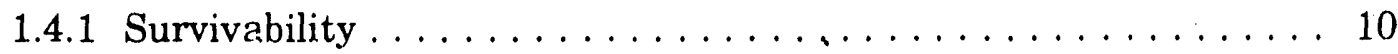

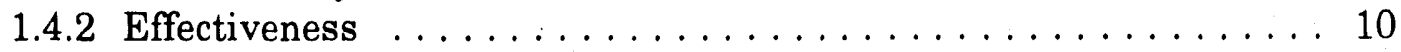

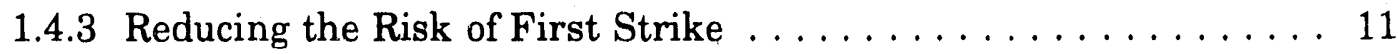

1.4.4 Reducing the Concentration of Warheads on Reentry Vehicles ... 11

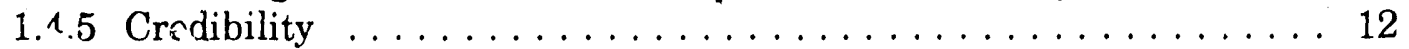

2 POSSIBLE PROVISIONS OF START II $\ldots \ldots \ldots \ldots \ldots \ldots \ldots \ldots$

2.1 Provisions Based on 50\% Reductions Beyond Start Limits . . . . . . . . 14

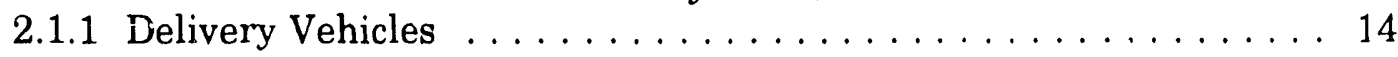

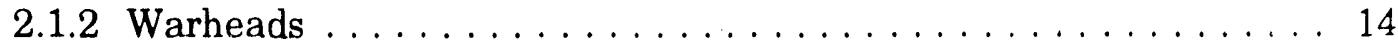

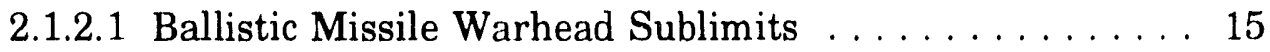

2.1.2.2 Warheads on Heavy ICBMs $\ldots \ldots \ldots \ldots \ldots \ldots \ldots$

2.1.2.3 Mobile Missile Warheads . . . . . . . . . . . . . . 16

2.1.2.4 Cruise Missiles . . . . . . . . . . . . . . . . . . 17 


\section{CONTENTS (Cont'd)}

2.2 Discussion ............................. 17

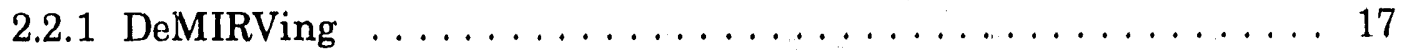

2.2.2 Warhead Limitation Options $\ldots \ldots \ldots \ldots \ldots \ldots \ldots \ldots \ldots$

2.2.2.1 Limitation of Attributed Warheads ............. 19

2.2.2.2 Limitation of Warheads Actually Deployed ......... 20

2.2.2.3 Limitation of the Total Number of Warheads . . . . . . . 20

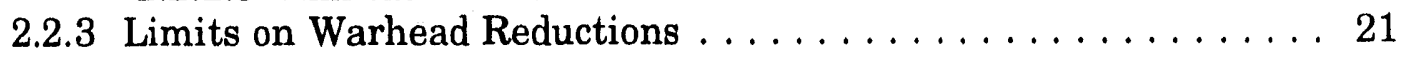

3 RESULTING U.S. FORCE STRUCTURE $\ldots \ldots \ldots \ldots \ldots \ldots \ldots \ldots \ldots$

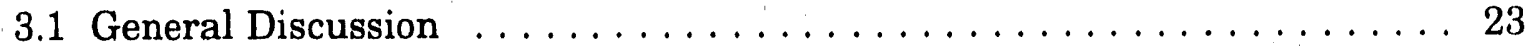

3.1 .1 Target Base ........................... 23

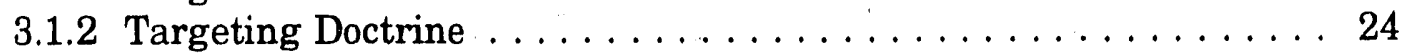

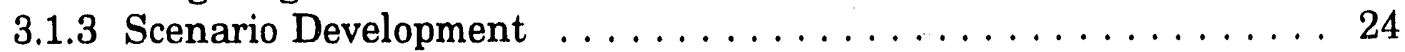

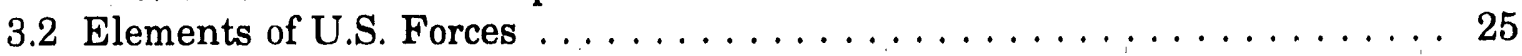

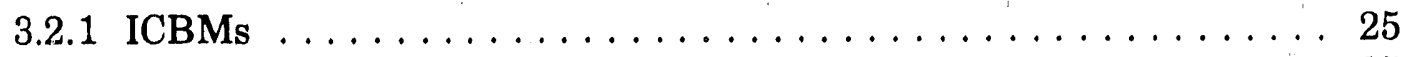

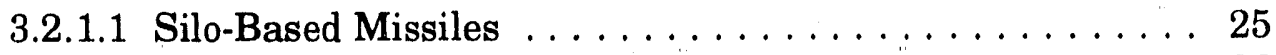

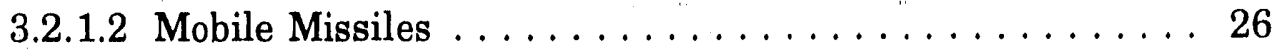

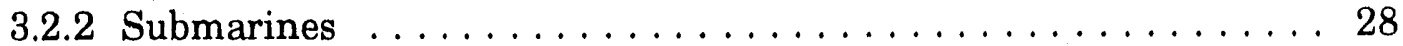

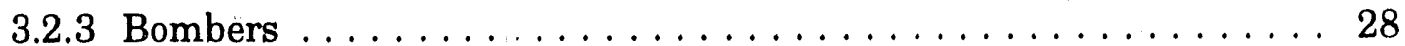

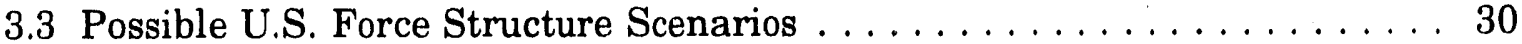

3.3.1 Maximum Land-Based Missiles $\ldots \ldots \ldots \ldots \ldots \ldots \ldots \ldots$

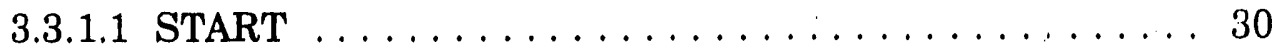

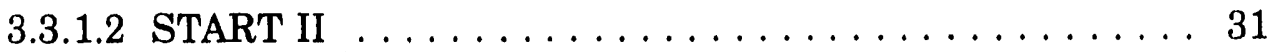

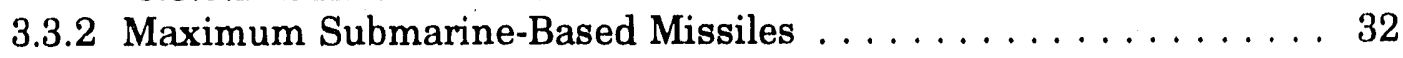

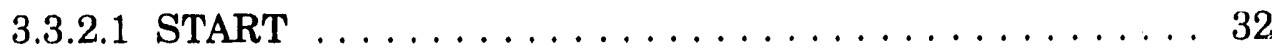

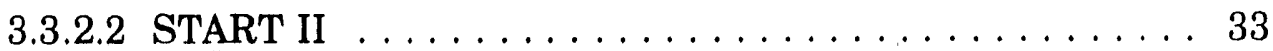

3.3.3 Elimination of Silo-Based Multiple-Warhead Missiles . . . . . . . 34

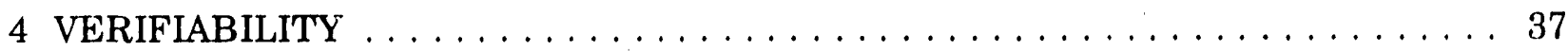

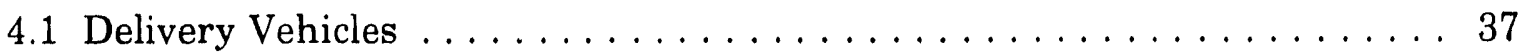

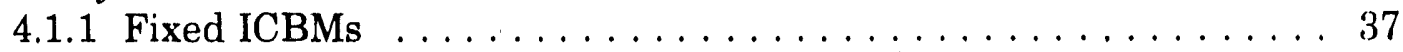

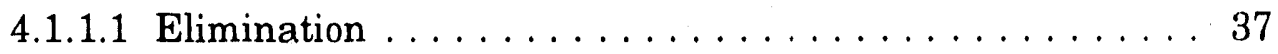

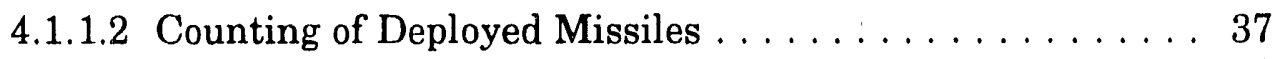

4.1.1.3 Nondeployed Missiles ................... 37

4.1 .2 Mobile ICBMs $\ldots \ldots \ldots \ldots \ldots \ldots \ldots \ldots \ldots \ldots \ldots$

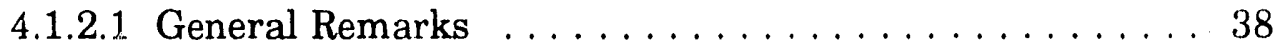

4.1.2.2 Road-Mobile Missiles . . . . . . . . . . . . . . . . . . . 39

4.1.2.3 Rail-Mobile Missiles . . . . . . . . . . . . . . . . 39

4.1 .3 SLBMs $\ldots \ldots \ldots \ldots \ldots \ldots \ldots \ldots \ldots \ldots \ldots \ldots \ldots \ldots \ldots$

4.1 .4 Bombers ............................... 40

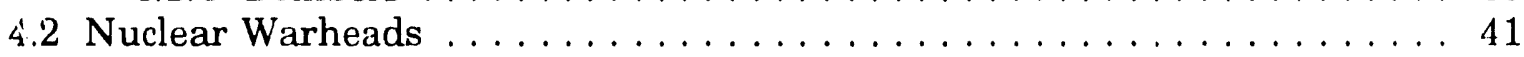

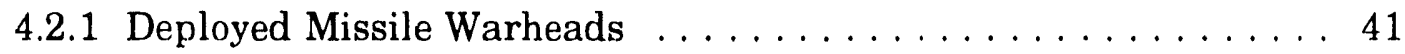




\section{CONTENTS (Cont'd)}

4.2 .2 Bomber Weapons $\ldots \ldots \ldots \ldots \ldots \ldots \ldots \ldots \ldots \ldots \ldots, 41$

4.2.2.1 Deployed Bomber Weapons ................ 41

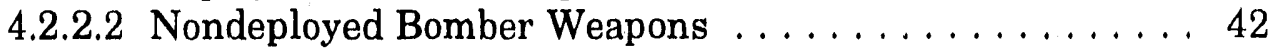

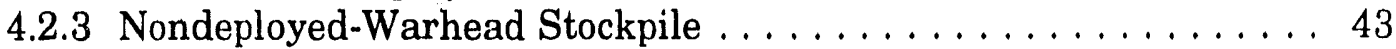

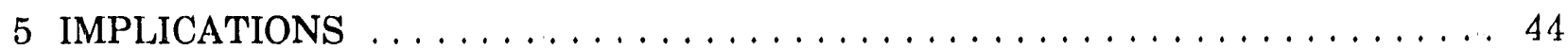

5.1 The Need for New Weapon Systems . . . . . . . . . . . . . . 44

5.1 .1 Reduced Numbers of Weapons $\ldots \ldots \ldots \ldots \ldots \ldots \ldots \ldots, \ldots 4$

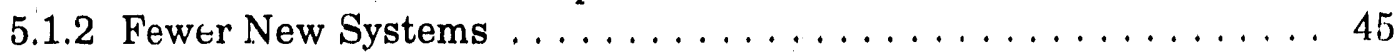

5.2 The Utility of Possible Treaty Provisions $\ldots \ldots \ldots \ldots \ldots \ldots \ldots \ldots$

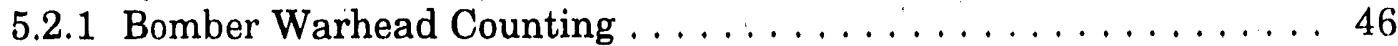

5.2 .2 Total Warhead Limitation $\ldots \ldots \ldots \ldots \ldots \ldots \ldots \ldots \ldots . \ldots 47$

5.2.3 Deployed Ballistic-Missile Warhead Limitations . . . . . . . . . . 47

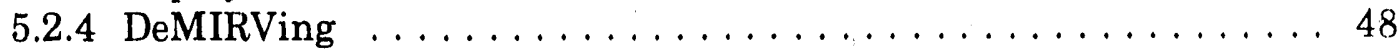

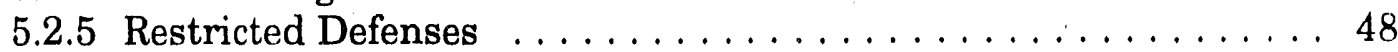

5.3 Implications for Warhead and Fissile-Material Production . . . . . . . . 49

5.4 Areas for Further Work $\ldots \ldots \ldots \ldots \ldots \ldots \ldots \ldots \ldots . \ldots \ldots$

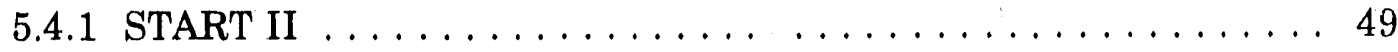

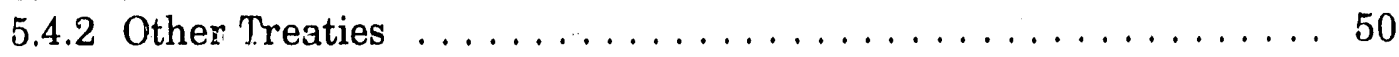

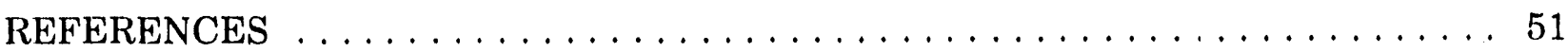

APPENDIX: $\quad$ START PROVISIONS $\ldots \ldots \ldots \ldots \ldots \ldots \ldots \ldots \ldots \ldots \ldots$

FIGURES

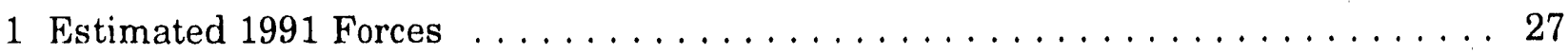

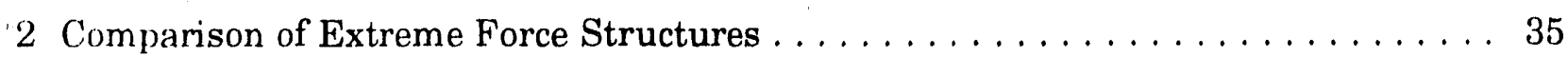

TABLES

1 Warhead Limitation Options $\ldots \ldots \ldots \ldots \ldots \ldots \ldots \ldots \ldots \ldots \ldots \ldots$

2 U.S. Strategic Force Structure at START Signature $\ldots \ldots \ldots \ldots \ldots \ldots \ldots$

3 Possible Force Structures Scenario: SAC Post-START Wish List $\ldots \ldots \ldots \ldots \ldots$

4 Possible Force Structures Scenario: Maximum Submarine-Based Missiles . . . . . 33

5 Comparison of Extreme Force Structures under START and START II . . . . . . 34 


\section{FOREWORD}

This report was originally written before the signing of the Strategic Arms Reduction Treaty (START) and before the dramatic changes in the Soviet Union that began in August 1991. The report was revised to reflect those events, and then revised again after President Bush's speech of September 27, 1991, and President Gorbachev's response. Events have been moving so swiftly that the author feels like Alice in Wonderland, running faster and faster just to stay in the same place.

The evolution in what was the Soviet Union is continuing, and by the time this report is printed, it will no doubt be out of date in terms of historic detail. It is thought that the basic conclusions will still hold true, regardless of the exact political structure. However, there is an underlying assumption that Soviet nuclear weapons will remain in the control of a single, centralized authority, and that the people in charge will be rational. Analysis of interactions with several nuclear powers in the former Soviet Union could lead to somewhat different conclusions than those identified in the present study.

Linda L. Gaines 


\section{LIST OF ABBREVIATIONS AND ACRONYMS}

$\begin{array}{ll}\text { ABM } & \text { Anti-Ballistic Missile (Treaty) } \\ \text { ACDA } & \text { Arms Control and Disarmament Agency } \\ \text { ALCM } & \text { air-launched cruise missile } \\ \text { ASW } & \text { anti-submarine warfare } \\ \text { B-1B } & \text { U.S. bomber type } \\ \text { B-2 } & \text { U.S. Stealth bomber } \\ \text { B-52 } & \text { U.S. bomber type (older than the B-1B) } \\ \text { CEP } & \text { circular error probable } \\ \text { CFE } & \text { Conventional Forces in Europe (Treaty) } \\ \text { DOD } & \text { U.S. Department of Defense } \\ \text { DOE } & \text { U.S. Department of Energy } \\ \text { ICBM } & \text { intercontinental ballistic missile } \\ \text { INF } & \text { Intermediate-Range Nuclear Force (Treaty) } \\ \text { JCS } & \text { Joint Chiefs of Staff } \\ \text { JSTPS } & \text { Joint Strategic Targeting Planning Staff } \\ \text { LTBT } & \text { Limited Test Ban Treaty } \\ \text { MIRV } & \text { multiple independently targeted reentry vehicle } \\ \text { MM } & \text { Minuteman (a U.S. missile type) } \\ \text { MX } & \text { U.S. "missile-experimental" or "Peacekeeper" missile } \\ \text { NPT } & \text { Non-Proliferation Treaty } \\ \text { NSDD } & \text { National Security Decision Directive } \\ \text { NTM } & \text { national technical means } \\ \text { OSI } & \text { on-site inspection } \\ \text { OSM } & \text { on-site monitoring } \\ \text { R\&D } & \text { research and development } \\ \text { RV } & \text { reentry vehicle } \\ \text { SAC } & \text { Sirategic Air Command } \\ \text { SALT } & \text { Strategic Arms Limitation Treaty } \\ \text { SDI } & \text { Strategic Defense Initiative } \\ \text { SIOP } & \text { Single Integrated Operational Plan } \\ \text { SLBM } & \text { submarine-launched ballistic missile } \\ \text { SLCM } & \text { sea-launched cruise missile } \\ \text { SNDV } & \text { strategic nuclear delivery vehicle } \\ \text { SRAM } & \text { short-range attack missile } \\ \text { SS-18 } & \text { Suviet heavy silo-based missile type } \\ \text { SS-24 } & \text { Soviet MIRVed rail-mobile missile } \\ \text { SSI } & \text { suspect-site inspection } \\ \text { START } & \text { Strategic Arms Reduction Treaty } \\ \text { U.S. } & \text { United States (of America) } \\ \text { USSR } & \text { Union of Soviet Socialist Republics } \\ \text { WH } & \text { warhead(s) } \\ & \end{array}$




\section{ACKNOWLEDGMENTS}

The author would like to thank the many persons who have reviewed this document in various stages of preparation, including G. Michael Houser, Alexander De Volpi, and Armando Travelli (Argonne National Laboratory); James Motley (Washington, D.C.); and Richard Bowen (U.S. Department of Energy, Office of Arms Control). Several reviewers were particularly helpful: Gerald Marsh (Argonne National Laboratory), Richard Davis (Science Applications International), Ruth Howes (Ball State University), and David Stein (U.S. Department of Energy, Office of Arms Control).

Many thanks also go to Argonne's Floyd Bennett and Margaret Clemmons for editing, to Laurel Culbert (and Jeanne Sirovatka, an Argonne summer stude nt from Princeton University) for graphics assistance, and to the staff of the Document Processing Center. 


\title{
START II: THINKING ONE MOVE AHEAD
}

\author{
by
}

\author{
L.L. Gaines
}

SUMMARY

\section{S.1 INTHODUCTION}

At their 1990 summit, Presidents Bush and Gorbachev issued a joint statement setting general goals for negotiation of a follow-on treaty to the Strategic Arms Reduction Treaty (START). President Bush's historic speech on September 27, 1991, reinforced these goals and specified several actions the United States (U.S.) would take. ${ }^{*}$ This report. examines possible provisions of START II and resultant force structures, together with their implications for achieving the summit goals, for verifiability, and for U.S. force planning. This look ahead will contribute to advance planning of appropriate negotiating positions, verification research and development $(R \& D)$, and force modernization and restructuring.

The signing of START is a remarkable milestone on the path of arms control. It is the first treaty to actually reduce strategic arms, and it provides for effective (and intrusive) verification that will set a precedent for future treaties. Although it loes not achieve the originally advertised $50 \%$ reductions in all strategic arms, it comes close to this goal in the most threatening category: deployed ballistic missile warheads.

The goals for post-START negotiations are to "reduce further the risk of outbreak of... nuclear war, and to ensure strategic stability... This will be achieved by seeking agreements that improve survivability, (and) remove incentives for a nuclear first strike...." The leaders further agreed to "seek measures to reduce the concentration of warheads on strategic delivery vehicles as a whole, including measures related to the question of heavy missiles and MIRVed ICBMs." ${ }^{\ddagger}$ President Bush's September 1991 speech reinforced the focus on landbased MIRVs.

\footnotetext{
${ }^{*}$ New York Times (national ed.), quoting President Bush, p. 1 (Sept. 28, 1991).

${ }^{\dagger} J$ Jint Statement on Future Negotiations on Nuclear and Space Arms and Furiher Enhancing Strategic Stability, reprinted in Arms Control Today (June 1990), p. 23.

${ }^{\dagger}$ Norris, R., and T. Cochran, "Making a Virtue of Necessity: START and Strategic Modernization," Nuclear Weapons Databook Working Paper 90-1, National Resources Defense Council, Washington, I).(.. ( May 15, 1990).
} 


\section{S.2 POSSIBLE PROVISIONS OF START II}

\section{S.2.1 Provisions Based on 50\% Reductions Beyond STAR'T Limits}

Delivery Vehicles. A tighter limit on deployed delivery vehicles under START II would do nothing towards the goal of deMIRVing, ${ }^{*}$ but it would give an incentive to remove silo-based missiles. Banning or deMIRVing the Soviet heavy missiles under START II (and not permitting replacement with large numbers of fixed, single-warhead ICBMs) would contribute more to stability than would further reductions.

Nondeployed delivery vehicles are not limited under START, except for mobile missiles, but their movements and storage are restricted. Similar provisions are assumed for START II.

Warheads. Bombers carrying gravity bombs or short-range attack missiles (SRAMs) are counted as one warhead, although they may carry many. Under START II, this "bomber loophole" could apply to a greater percentage of total warheads. More realistic warhead accounting would reduce the incentive for B-2 deployment for an assumed penetration mission. Because the utility of START's separate sublimit on mobile intercontinental ballistic missile (ICBM) warheads is unclear (mobile missiles are survivable [capable of surviving a surprise attack], and hence stabilizing), no further reduced sublimit is assumed under START II.

\section{S.2.2 Discussion}

DeMIRVing. Severe restrictions on destabilizing fixed MIRVed land-based systems are most consistent with the stated goal of crisis stability. START II could reduce the number of warheads permitted on silo-based ICBMs.

Warhead Limitation Options. There are three possible variants on warhead limitations under START II: (1) limitation of attributed warheads, (2) limitation of actually deployed warheads, and (3) limitation of the total number of warheads in U.S. and Soviet arsenals, with the remainder dismantled. The last two variants could have long-term advantages, but they may not be critical to achieving strategic stability.

\footnotetext{
${ }^{*}$ MIRV = multiple independently targeted rcentry vehicle.
} 


\section{S.3 RESULTING FORCE STRUCTURE}

\section{S.3.1 General Discussion}

The force structure under both START and START II must have "structural stability" so that changes in the world political environment do not put the United States at a disadvantage. In addition, it must allow formulation of the Single Integrated Operational Plan (SIOP). The treaties could, however, lead to changes in the SIOP by reducing the target base and altering targeting priorities. The changes in Eastern Europe and the centrifugal forces among the Soviet republics are likely to be even more important drivers of changes in the SIOP.

This section identifies available weapon systems and examines several possible (extreme) post-START II force structures. These are maximum land-based missiles, maximum suhmarine-based missiles, and elimination of fixed MIRVed systems. Only U.S. force structures are addressed here; similar work has been proposed for Soviet forces.

\subsubsection{Elements of U.S. Forces}

ICBMs. Under some force structures examined, MX ("missile-experimental" or "Peacekeeper") missiles could have been deployed on rail-cars. Elimination has also been considered. Mobile missiles, whether MIRVed or not, are more survivable than silo-based ICBMs, if appropriately based and properly operated, and are, therefore, an acceptable part of a stable force mix. The decision to deploy mobile ICBMs on either side should be based on their role in fulfilling missions not covered by other survivahle systems. The president has now canceled both U.S. mobile missile programs.

Submarines. Submarine-launched ballistic missiles (SLBMs) are assumed to be capable of carrying out the missions previously reserved for the MX, because of the accuracy and yield available with the D-5 SLBM.

Bombers. Bombers are slow fliers compared with missiles. Therefore, bombers cannot be assigned prompt missions under the SIOP.

\section{S.3.3 Possible U.S. Force Structure Scenarios}

Maximum Land-Based Missiles. This scenario is based on a post-START force structure postulated by the Strategic Air Command (SAC). Retaining all new systems under S'TAR'I' II then places serious constraints on submarines. 
Maximum Submarine-Based Missiles. Timely negotiation of START II would allow even the most submarine-dependent force structure to be achieved with the vessels already in the pipeline, if some Poseidon submarines could be kept operating until S'TART II reductions began.

Elimination of Silo-Based Multiple-Warhead Missiles. Under this scenario, all fixed MIRVed missiles would be eliminated under START II, perhaps as the result of trading the MX (and possible additional concessions) for the SS-18. This is now considered a likely scenario.

Comparison of Scenarios. The maximum submarine-based missile scenario is highly MIRVed, but it is still highly survivable. The maximum land-based missile sconario is less highly MIRVed, but the fixed land-based missiles in that scenario are vulnerable to a first strike. Eliminating all fixed MIRVs would maximize stability.

\section{S.4 VERIFIABILITY}

The concern here is whether START verification methods will be adequate to ensure against the smaller violations that would be militarily significant under START II.

\section{S.4.1 Delivery Vehicles}

Fixed ICBMs. Verification of the removal of fixed ICBMs from silos can be accomplished by national technical means (NTM). On-site inspection can verify both removal of missiles from silos and missile destruction. Verification of spare missiles can be accomplished by initial on-site inspection, frillowed by continuing observation using NTM. Nondeployed missiles at cold-launch sites, but not hot-launch sites, could be a legitimate concern. The likelihood of being damaged during an initial exchange decreases the value of spare missiles at these sites.

Mobile ICBMs. Verification of Soviet road-mobile missiles will not be easy, hecause these are by design difficult to track. Counting trains for rail-mobile missiles might be somewhat easier if they were readily distinguishable from other trains or were kept at their bases, as is now planned. U.S. mobile missiles would have been based in restrictive modes, making them easier to verify. Unauthorized missiles entering declared bases conld be detected by authenticable tagging and perimeter monitoring.

Covert mobile missiles left under START would be doubly significant under START II. Production monitoring can ensure against future uncertainties in mobile missile production but is expensive and cannot verify past production. Challenge inspection should be retained to deter against covert missiles and launchers. 
SLBMs. Few ports are equipped to load nuclear submarines, and loading of additional missiles at sea is extremely unlikely. Therefore, submarines could be monitored in port, and subsequent loading and unloading witnessed after initial inspection.

Bombers. On-site inspections teams could spot-check to make sure that non-ALCM bombers tested with air-launched cruise missiles (ALCMs) were not carrying covert ALCMs.

\section{S.4.2 Nuclear Warheads}

Using START counting rules under START II would remove most requirements for actually counting warheads. Limiting actual warheads under START II would pose more serious verification concerns.

Deployed Missile Warheads. Actual loading of warheads on missiles will be spotchecked during on-site inspection. Counting at initial downloading, supplemented by spotchecks and counting whenever the missile was removed and replaced, would be adequate to verify warhead numbers on downloaded missiles. Uploading could be detected but not prevented. Final START limits on downloading minimize the amount of uploading possible.

Bomber Weapons. Counting would be necessary to verify limits on warheads actually deployed, unless each bomber were attributed its maximum capacity, Exhibition would be necessary initially to verify the capacity of each type uf aircraft. Nondeployed stocks if bomber weapons could affect only a protracted conflict.

Guidelines for determining ALCM type or range by externally observable characteristics during on-site inspection would aid verification.

Nondeployed Warhead Stockpile. Verification of a limit on the nuclear warhead arsenal would be extremely difficult. It would require cradle-to-grave tracking of weaponsgrade materials to ensure against clandestine warhead production. A reliable accounting of past production would also be required to ensure against covert stockpiles that could eventually represent militarily significant quantities.

\section{S.5 IMPLICATIONS}

\section{S.5.1 Need for New Weapon Systems}

Timely completion of START II could reduce the need for deploymenit of new wearon systems. We distinguish between reductions in the numbers of weapons required and reclucted need for new or modernized systems. The total numbers of weapons required will 
decrease because there will be fewer targets, and targeting policy can be expected to change as events in the Soviet Union evolve. Selective modernization of our forces may be needed if doing so improves strategic stability and makes our forces or their command, communication, and contröl more survivable.

\section{S.5.2 Utility of Possible Treaty Provisions}

Bomber Warhead Counting. More realistic warhead counting would provide more certainty about the current status and would contribute to stability. Counting could be made $\mathrm{m}^{r}$ re realistic either by actually counting warheads or by using counting rules that more closely approximate actual loadings.

Total Warhead Limitation. A ceiling on the total number of warheads in U.S. ar.d Soviet arsenals would probably be difficult to negotiate and verify. A START II agreement that greatly enhanced strategic stability could probably be accomplished faster if it did not need to address this complex and separable issue.

Deployed Missile Warhead Limitations. Limiting warheads on fixed missiles would contribute to the stability that is a major goal of START II.

DeMIRVir.g. The critical element would be to deMIRV vulnerable systems. An appropriate provision would eliminate or irreversibly deMIRV fixed ICBMs within SNDV limits and let strategic planners allocate their remaining warheads.

Restricted Defenses. Restrictions on defensive systems might reduce costs and eliminate an arms-race instability if the Soviet Union again became an adversary.

\section{S.5.3 Implications for Warhead and Fissile-Material Production}

Even under START, the number of strategic nuclear warheads needed by the United States is boundea. Follow-on treaties would further bound the number of warheads. Costs and potential benefits of marginal improvements in warhead design, as well as the technical feasibility of reusing warheads in different, possibly existing reentry vehicle (RV) packages, should be examined.

Even continued warhead production would require little or no additional fissile material production. A cutoff would therefore impose no constraints, beyond those caused by agreed-upon warhead reductions, on U.S. defense programs. Tritium must be replenished

periodically, but any reduction in warhead requirements will draw out current supplies and minimize future production requirements. 


\section{S.5.4 Areas for Further Work}

A more cietailed analysis should be undertaken, for both the United States and the Soviet Union, to quantify and develop future force structures that minimize crisis instability. Further study should also include implications of the full range of possible provisions that would increase stability under START II.

Examination of the potential interrelationships among treaties, in conjunction with consideration of several questions about the best way to carry out arms reductions in a rapidly changing world, would help direct arms-control research to the most fruitful areas. 


\section{INTRODUCTION}

\subsection{PURPOSE}

At their summit meeting in the spring of 1990, Presidents Bush and Gorbachev issued a joint statement expressing their intentions to continue the process of strategic arms control beyond the Strategic Arms Reduction Treaty (START), which was eventually signed in July 1991, toward agreement on further reductions. They set general goals for negotiation of a follow-on treaty to START, which has been called START II. President Bush's historic speech on September 27, 1991, reinforced these goals and specified several actions the U.S. would take. ${ }^{1}$ It is the purpose of this report to examine possible provisions of START II and the implications of those provisions for achievement of the goals set at the 1990 summit, for verifiahility, and for U.S. force planning. This look ahead will contribute to advance planning of appropriate negotiating positions, verification research and development (R\&D), and force modernization and restructuring.

\subsection{ORGANIZATION}

Section 1 of this report describes the goals for a START II treaty and possible means for achieving them. Section 2 postulates one set of provisions for such a treaty, while Section 3 examines force structures for the U.S. that could result from adoption of a treaty with these provisions. Section 4 examines the adequacy of methods for verifying START II. Section 5 suinmarizes the implications of a START II treaty as postulated.

\subsection{START: STATUS AND UTILITY}

There has been much attention focused on the July 1991 signing of START in Moscow. The few issues remaining at that time were resolved because of the determination of the two presidents. The major provisions of START are summarized in the Appendix.

The signing of START is a milestone on the path of arms control. It is the first treaty to actually reduce strategic arms, and it provides for effective (and intrusive) verification that sets a precedent for future arms control treaties. Even so, START is a disappointment to those who argue that it does not go far enough. ${ }^{2}$ The actual reductions in some categories are less than the $50 \%$ originally proposed, and some had hoped that warheads would actually be eliminated. But the most destabilizing systems, the heavy MIRVed ${ }^{*}$ missiles, are reduced by $50 \%$. START is a significant first step that will enable further progress. It can be argued that further reductions should be accomplished without ireaties, much as both the Inited States and the Union of Soviet Socialist Republics (USSR) are now planning for reductions in tactical nuciear weapons. ${ }^{1,3}$ However, the present

\footnotetext{
"MIRV = multiple independently targeted reentry vehicle.
} 

volatility of the Soviet Union makes formal assurances that strategic arms reductions will
not be reversed essential.

\subsection{START II: GOALS}

The guals stated for post-START negotiations by Presidents Bush and Gorbachev at the June 1990 summit are to "reduce further the risk of outbreak of... nuclear war, and to ensure strategic stability.... ${ }^{4}$ This will be achieved by seeking agreements that improve survivability, (and) remove incentives for a nuclear first strike...." agreed to "seek measures to reduce the concentration of warheads on strategic delivery vehicles as a whole, including measures related to the question of heavy missiles and MIRVed ICBMs." 4 President Bush's September 1991 speech reinforced the focus on land-based MIRVs. ${ }^{1}$ The following subsections address issues associated with the achievement of these goals.

\subsubsection{Survivability}

The joint statement ${ }^{4}$ cites inproved survivability as the first means for achieving the goals. To be survivable, a strategic system (and its command and control systems) must not be subject to destruction by a surprise attack. Survivability can be enhanced by increasing mobility or hardness. Silo-based intercontinental ballistic missiles (ICBMs) are generally not considered to be survivable, because they cannot ride out an attack. (Two interesting and different theories are brought out in Section 3.2.1.1.) As soon as survivability is acknowledged to be a necessary attribute for our strategic arms, the role of silo-based ICBMs must be seriously reexamined. Whether START II specifies their reduction or not, both parties should consider, ihasing them out as major strategic forces (although reasons could be envisioned for keeping a small force of single-warhead ICBMs) to fulfill the goals in the joint statement. It has been argued that single-warhead, fixed ICBMs are not really destabilizing because two warheads would be targeted on each one. However, this argument is not compelling when crisis stability is quantified and scenarios for riding out an attack are compared to launch-on-warning.

\subsubsection{Effectiveness}

Additional stability can be achieved by assuring the ability of surviving weapons to carry out their missions. This ability can, of course, be enhanced by improving weapon

\footnotetext{
"The President's Commission on Strategic Forces ("Scowcroft Commission") has defined stability as "It the condition which exists when no stral gic power believes it can significantly improve its situation by attacking first in a crisis or when it does not feel compelled to launch its stratreric weapons in order to avoid losing them" (Ref. 5). This is the definition of crisis stability rather than arms-race stability. The term stability will mean crisis stability in this report, unless otherwise specified.
} 
system performance, but it can also be enhanced by restricting or targeting certain defenses against those systems. For example, the B-1B or B-52 bomber types could be considered sufficiently effective, even for an assumed penetration mission, that construction of an entire fleet of B-2s would be unnecessary if Soviet air defenses were expected to be significantly weakened before any planes arrived or if START II restricted air defenses.

\subsubsection{Reducing the Risk of First Strike}

The joint statement also aims to enhance stability by reducing the risk of a first strike. What are the incentives for first strike or early use, and how could they be reduced? The major incentives are as follows:

- Using our vulnerable systems before they can be destroyed (launch-onwarning or launch-under-attack) and

- Destroying opposing weapons likely to be used against us (damage limitation).

These incentives can be reduced by reducing the number of systems that are vulnerable; there is no need for immediate launch of survivable systems. Neither side can destroy opposing weapons if they're survivable, so the second incentive is also reduced by having survivable systems on both sides. As John Deutch stated, "In the long run it is survivability that preserves the stability of the strategic nuclear balance; it is survivability that determines that no decisive, calculable advantage is gained by a first strike." 6

While both sides will retain the technical capability for a first strike, the risk that it will be used is decreasing because the global political situation is becoming more open and less adversarial. ${ }^{7}$ As international cooperation grows and economic interests of former opponents intermingle, incentives for conflict can be expected to decrease.

\subsubsection{Reducing the Concentration of Warheads on Reentry Vehicles}

The summit statement ${ }^{4}$ cites reduction of the concentration of warheads on reentry vehicles (RVs) as a way to improve stability. This raises the issue of MIRVed systems in general, although it emphasizes heavy missiles and ICBMs (with silo-basing possibly implied). The value of deMIRVing survivable systems is not obvious. This was recognized by President Bush, who has now clearly focused on reduction of land-based MIRVs only, leaving submarine-based missiles untouched. ${ }^{1}$

DeMIRVing mobile missiles might, however, reduce the precision needed for counting during verification, because a small number of uncounted single-warhead missiles may not be militarily significant. If we were unsure about survivability, deMIRVing and increasing the number of platforms could be useful. However, such options could also be expensive on a cost-per-warhead basis (the options of loading Trident submarines incompletely or building 
small submarines illustrate this ${ }^{*}$ ) and possibly of limited utility; the costs shnuld bo compared to the potential benefits.

\subsubsection{Credibility}

The means stated in the summit statement for achieving stability are incomplete. Survivability is necessary but insufficient. In addition, the force must be credible, meaning that the weapons in place could accomplish the goal of deterrence. Deterrence means being perceived as being able and willing to retaliate in the event of an attack, either in a single retaliatory strike or more extensively. Current nuclear warfighting doctrine requires that the target base of possible militarily important targets (which needs to be defined carefully) be covered with appropriate weapons with a carefully considered damage expectancy. This relatively complete coverage has been integral to Joint Strategic Target Planning Staff (JSTPS) planning in the past, although not all Single Integrated Operational Plan (SIOP) options call for launching against all targets. (A more complete discussion of the history of the SIOP and how it works is given in Ref. 9.) General David Jones, retired chairman of the Joint Chiefs of Staff (JCS), stated, "The targeting is an output of the basic strategy, and the basic strategy is to keep at risk essentially the entire Soviet nuclear and conventional capability with nuclear weapons." 10

To be consistent with the historical JSTPS targeting policy, START II would need to permit a force structure that allowed coverage of a significant fraction of the entirc target base. However, the number of targets could be drastically reduced, and complete coverage might not be necessary or possible (see Section 3.1 below). With this in mind, this report examines one set of potential treaty provisions and several possible resultant force structures under STARI II. It then examines verification issues and implications, given a plausible range of items to be verified.

\footnotetext{
*As Secretary of Defense Cheney has said (Ref. 8), "If you were to deMIRV the sea-based leg, you'd also then be in a position where you're going to spend a lot of money buying one submarine that would have 16 missiles on it, each with one warhead... that gets to be a very expensive way to deploy the force."
} 


\section{POSSIBLE PROVISIONS OF START II}

Given the background provided in Section 1, one can speculate on what START II might do. What systems will be limited, and to what levels? Will there be provisions without numerical limitations? This study examines the most obvious possibility - that START' precedents are followed and that the nominal objective of START II is a further 50\% reduction in strategic weapons. This possibility was recently suggested by President Gorbachev: "We propose to the United States immediately upon the ratification of the STAR'T treaty to embark on intensive negotiations on further radical reductions of the strategic offensive weapons, approximately to halve them." ${ }^{13}$ It is also consistent with force levels being considered by I)epartment of Defense analysts. The purpose of this approach is to examine the implications of these provisions and variants on them. The results must then be compared with analyses of other possible provisions, such as constraints on force mixes, or other numerical limits, to select the most useful directions for negotiating START II provisions.

Other possible provisions for START II would address the structure and quality of the forces, rather than the quantity. One Soviet analyst stated that, "stage two should focus not so much on numerical reductions as on profound structural reorganization of Soviet and U.S. strategic forces, and on blocking destabilizing arms developments. ${ }^{11} \mathrm{He}$ also suggested improved communication and additional restrictions to increase stability. These restrictions include a ban on counters to purely retaliatory systems; ${ }^{*}$ a ban on all nuclear-armed sealaunched cruise missiles (SLCMs), because they have strategic range ${ }^{\dagger}$ a prohibition against siting submarines within 1000-1500 km of coastlines; restrictions on submarine patrol areas; and a ban on missile tests with depressed or short time-of-flight trajectories. Other analysts emphasize the need to restrict air defenses and address the competition for technological breakthroughs.

Another possible provision to improve crisis stability and increase confidence would change alert provisions to reduce the "hair trigger" problem. Eighty-five percent of U.S. ICBMs were until recently said to be ready for launch within three minutes. ${ }^{12}$ Some, but not all, missiles and all bombers were taken off alert by President Bush. ${ }^{1}$ The United States's "missile-experimental" or "Peacekeeper" (MX) missiles remain on alert.

\footnotetext{
"Retaliatory systems are claimed to include mobile missiles, as well as single-warhead ICBMs in silos.

${ }^{t}$ The U.S. will now be removing these unilaterally and putting them in storage (Ref. 1).
} 


\subsection{PROVISIONS BASED ON 50\% REDUCTIONS BEYOND S'TART LIMITS}

\subsubsection{Delivery Vehicles}

Strategic nuclear delivery vehicles (SNDVs) include ballistic missiles and bombers. A $50 \%$ reduction beyond the START limit of 1600 SNDVs would lead to 800 SNDVs under STAR'T II. Setting a limit of 800 SNDVs does nothing toward the goal of deMIRVing stated at the 1990 summit, because the number of permitted delivery vehicles is so far below the number of warheads; therefore, setting such a limit might be of limited utility. Richard Garwin has stated (as quoted by Budiansky) that "a limitation on the number of launchers is the last thing you want. What you really want to do is reduce the number of warheads facing us." ${ }^{12}$ One analyst has even considered the possibility of relaxing the START SNDV limits. ${ }^{13}$ Lowering the limit would, however, give an incentive for removing silo-based missiles, which are generally considered to be destabilizing. Most of the force structures for the U.S. under postulated START II provisions will be seen to have no trouble complying with a limit of 800 SNDVs. Only force structures with large numbers of single-warhead ICBMs are constrained.

A potentially troubling point is that as the number of SNDVs is reduced, any remaining tactical systems, including the long-range nuclear SLCMs that will be stored, can be perceived as being more important in a protracted conflict. Although the U.S. presumably does not currently include these in the SIOP (because SIOP and general-purpose forces are not mixed), they could conceivably be utilized as strategic weapons, so consideration of these systems may be necessary. A separate treaty covering tactical systems might be a useful companion to START II to lock in unilateral reductions and complete elimination.

Nondeployed (spare) delivery vehicles are not limited under START, with the exception of mobile missiles, but their movements and the numbers stored near deployment sites are restricted. These restrictions effectively limit the rate of possible deployment. It is assumed that similar provisions will apply for START II. Numerical limitations could be imposed if launching from canisters or concrete tubes is a real danger. Missiles on submarines in overhaul were at one time considered for exclusion from counting under START, but they will be counted under the final treaty. No exclusion is assumed for START II.

\subsubsection{Warheads}

Halving the START limit of 6000 accounted deployed warheads would result in a limit of 3000 warheads under START II. ${ }^{*}$ This number is used as the basis for discussion, although it may not be optimal. Several experts have suggested numbers of 3000 or less as goals for negotiation. General David Jones, for instance, stated that "roughly 2000-3000

\footnotetext{
${ }^{*}$ The Soviet Union has announced that it will reduce its strategic arsenal to 5000 deployed warheads under START (Ref. 3).
} 
strategic weapons would be sufficient."10 Paul Nitze cited 3000, and Edward Warner 2400, while Harold Brown thought that as few as 1000 would be sufficient under sumo circumstances, ${ }^{14}$ and Robert McNamara placed the lower limit at 500-1000. ${ }^{13}$ These estimates were made when the Soviet Union was a more apparent threat than it is now. As one recent commentator put it, "The... weakening of the Soviet Union /by the coupl as a competing nuclear force in effect rendered much of the American arsenal meaningless...."15 Lower estimates are becoming more popular.

START accounts for all warheads on deployed ballistic missiles at their declared loadings and counts bombers carrying air-launched cruise missiles (ALCMs) as a fixed number of warheads (see Section 2.1.2.4). Bombers carrying gravity bombs or short-range attiack missiles (SRAMs) are counted as only one warhead, altinough they may actually carry many more, leading to what has been called the "bomber loophole." If the START counting rules still applied under START II, the bomber loophole could account for a greater percentage of total warheads, and therefore might be c'snsidered more important, depending on the missions envisioned for the bombers. The incentive for B-2 bumber deployment for an assumed penetration mission if bombers count as one warhead and the number of targets is large is argued to be high. General John Chain, commander of the Strategic Air Command (SAC), requested 75 B-2s with 16 weapons each, because "forty-nine hundred missile-carried warheads are not enough to destroy the Soviet Union."14 Fewer weapons could be perceived to be required if the target set were reduced (destruction of the Soviet Union may be more than required) or defenses were assumed to be seriously damaged by the time bombars arrived. If actual warheads were counted, or if bombers carrying gravity bombs or SRAMs were accounted for with some more realistic number of warheads, then the B-2 bomber would not he a vehicle for carrying a large number of uncounted warheads. House Armed Services Committee chairman Les Aspin has been reported as favoring a warhead number around four or five. ${ }^{16}$

START also includes sublimits on several types of warhead deployments. It is assumed here that START II will include similar sublimits.

\subsubsection{Ballistic Missile Warhead Sublimits}

Halving the START sublimit of 4900 warheads on ICBMs and ballistic missile submarines would lead to a 2450 sublimit on the sum of ICBM and SLBM warheads. The United States at one time proposed a 3000-3300 sublimit on ICBM warheads under START; the Soviet Union then proposed a corresponding limit on submarine-launched ballistic missile (SLBM) warheads. Therefore, an additional sublimit of 1.650 on both ICBM warheads and SLBM warheads could have been included in START II, if both the U.S. and Soviet Union START positions were agreed on and then halved. The sublimit on submarine warheads would have been very difficult for the U.S. to agree to, because it would have significantly constrained the most survivable leg of the U.S. strategic Triad (see Section 4). 


\subsubsection{Warheads on Heavy ICBMs}

START sets a limit for the Soviet Union of 1540 warheads on 154 heavy missilar, or half of their current levels. The U.S. has no heavy missiles. Half of the START limit would be 770, but banning the Soviet heavy, silo-based missile type SS 1.8 would be a much morce significant contribution to stability, if the Soviets could be persunded to agree." Patul Nitzo wants to see the SS-18 eliminated because it is the "most destabilizing" nuclear "eapon. ${ }^{17}$ If the Soviets are serious about the stated START II goal of increased stability, they might consider eliminating their SS-18s, perhaps in exchange for the United States's MXs. "Such a trade would be beneficial to both parties, because it would eliminate the most threatening opposing systems. If it were considered unfair because the U.S. has "only" 50 MXs and the Soviets will have 154 SS-18s, the U.S. could offer an additional concession, such as agreeing not to deploy its full-scale Strategic Defense Initiative (SDI). However, bean-counting arguments miss the point and obscure the real objective of entancing stability. Aftor President Bush's speech, a U.S. Department of Defense (DOD) spokesman asserted that "this is not an old-style numbers game, in which negotiators try to determine whether exchanges are symmetrical or fair."18 Spurgeon Keeney, Arms Control Association president and former deputy director of the U.S. Arms Control and Disarmament Agency (ACDA), agrees that banning fixed-based MIRVs (a.g., the MX and SS-18) would improve stability. ${ }^{\text {ig }}$ President. Bush's recently announced goal of eliminating land-based MIRVs is essentially equivalent to eliminating fixed MIRVs, because the Soviets are granting his request to hold their SS-24 rail-mobile missiles (with 10 warheads each) in their rail garrisuns, ${ }^{1,3}$ A scenario with no fixed MIRVed missiles is examined in Section 3.3.

The Soviets have been reported to have suggested trading the MX for their SS-24. Senator Sam Nunn points out that this trade assumes that the MX is seen as potentially mobile, which is how it is considered under START, but Stephen Hadley, assistant secretary of defense for international security policy, reminds us that the mobile MX is a "paper program." ${ }^{16}$ It is even more artificial now that President Bush has dropped the rail-mubile MX program. ${ }^{1}$ Although Edward Warner has called this "a terrific trade," ${ }^{13}$ it would still letave the problem of eliminating the destabilizing SS-18s.

\subsubsection{Mobile Missile Warheads}

START includes a sublimit of 1100 warheads (WHs) on mobile ICBMs. The purpose of any further sublimit within the overall WH limits is unclear, since these systems aro survivable and, hence, contribute to stability. It is to the mutual advantage of both treaty

\footnotetext{
"START prohibits downloading of heavy missiles, presumably because of fears of roloading. DeMIRVing (downloading to one warhead) could be made irreversible, but each missile would then have a very great range and be capable of carrying an extremely high-yield warhead. Therefore, elimination is preferable.

'Answering questions about President Bush's Sept, 27, 1991, speech, Secrotary of Defense (hency said "They'd have to give up things like the SS-18. We'd give up things like Peacekeeper...." (Ref'. 8 ).
} 
parties for either to deploy as many of its permitted warheads as possible on survivable systems. Therefore, it will be assumed that no redustion of the mobile missile warhead sublimit is called for under START II. The point may now be moot, because the U.S. has dropped both mobile ICBM programs, and the Soviets do not plan on expanding their mobile missile arsenals, ${ }^{1,3}$

\subsubsection{Cruise Missiles}

Cruise missiles are counted as warheads under START, presumably because they require another vehicle to carry them within striking range. There is no numerical sublimit on the number of cruise missiles within the 6000-warhead limit. Each U.S. bomber carrying long-range (ovor $600 \mathrm{~km}$ ) nuclear ALCMs counts as 10 warheads, al though the treaty permits as many as 20 ALCMs to be carried, up to a maximum of 150 bombers. (The corresponding numbers for the Soviets are 8 and 16 ALCMs, on up to 180 bombers.) Additional bombers would be counted with their actual loads, although it is unclear how loads would be determined and verified unless the maximum load for the bomber type were determined and assumed.

Nuclear SLCMs are not included in START limits, but both sides agreed to declare actual holdings of those with ranges over $600 \mathrm{~km}$, which are not to exceed 880 . Data will also be exchanged concerning SLCMs with ranges of $300-600 \mathrm{~km}$. No verification is included. Concerns about the possible utility of long-range SLIJMs for strategic missions (al though they are not included in the SIOP) could be alleviated by counting SLCMs as warheads under START II or by limiting them under a separate tactical weapons treaty. This issue may also be moot, because the U.S. has announced plans to remove sea-based tactical nuclear weapons. SLCMs will, however, be retained in storage.

\subsection{DISCUSSION}

\subsubsection{DeMIRVing}

Various analysts have suggested elimination of MIRVed missiles - land-based, nobile, stationary, or all of them. In 1990, the Bush administration proposed that START II eliminate all land-based missiles with multiple independently targetable reentry vehicles (MIRVs). ${ }^{20}$ The president has recently 1 ziterated this goal. Paul Nitze, Paul Warnke, and Edward Warner all expressed agreement with the 1990 proposal, while Brent Scowcroft favored banning only MIRVed mobile missiles. ${ }^{21}$ President Gorbachev, in a letter to President Bush, proposed a ban on all MIRVed missiles, including sea-based ones. ${ }^{22}$ Les Aspin, House Armed Services Committee chairman, favors a ban un all mobile strategic missiles. 16

Severe restrictions on destabilizing fixed MIRVs and reductions of all fixed ICBM systems are most consistent with the stated goal of crisis stability under START II. 
START II could set specific limits on silo-based ICBMs, reducing the number of warheacks permitted on them so that those remaining were deMIRVed. For the purpuse of" aconmplishing START II goals, the two weapons tipi must be oliminated are the U.S. MX and the Soviet SS-18, both of which are significan contributors to crisis instability.

Elimination of, or a strict sublimit on whrheads on, MIRVed fixed ICBMs (prithins to 200 or fewer" would greatly enhance stability because it would provide considerable impetus to deMIRV and/or reduce fixed ICBMs. No such limit is included under START, but it is suggested here for inclusion under S'TART II. START II could follow the SALT II and START precedent and place a limit on the number of actual warheads on any SNDV (10 for ballistic missiles, 20 for bombers). The utility of a ceiling is clear, but tighter limits for survivable systems would be of questionable utility; it would probably make more sense to allow each treaty party to decide its own force structure, within general restrictions that encourage stable force configurations.

START limits the number of systems and the total number of warheads that can be downloaded, and it bans deployment of a new missile type with more warheads than on a downloaded type. The limits prevent uploading concerns from becoming militarily significent; the ban serves as a ratchet lowering the maximum number of RVs on a missile. Heavy missiles cannot be downloaded.

Under START II, the presidents propose to "seek measures to reduce the concentration of warheads on strategic delivery vehicles as a whole, including measures related to the question of heavy missiles and MIRVed ICBMs." One way to reduce the concentration of WHs on SNDVs would be to eliminate MIRVed systems. Another way would be to download (reduce warheads) or deMIRV (reduce to a single WH) MIRVed systems. However, this option is specifically limited by START for all missiles and prohibited for heavy missiles. In this instance, agreed-upon START provisions may not be thoroughly consistent with the goals of START II, and slightly different provisions for START II could be appropriate.

Demonstrably irreversible methods for downloading could alleviate uploading concerns. Such concerns were the reason for the START requirement that systoms downloaded by more than two RVs be equipped with a new front-section platform (hus). Further downloading could be permitted under START II as an intermediate step towards elimination if confidence in irreversibility were not sufficient to assure stability.

One incentive for downloading is to allow the services to keep existing systoms (keeping costs down) and maintain commands while reducing the number of warheads, in compliance with a treaty. However, it can be argued that stability increases as the number of vulnerable targets decreases; keeping the same vulnerable missiles but reducing the number of warheads on each may then have dubious value. Spreading warheads on more vulnerable missiles would decrease stability. 


\subsubsection{Warhead Limitation Options}

The limit on the total number of warheads will most likely be reduced again under START II, but there are three possible variants: (1) limitation of attributed warheads, (2) limitation of warheads actually deployed, and (3) limitation of the total number of warheads, with the remainder to be dismantled. The last two variants might be difficult to negotiate, because they go counter to the START precedent of using counting rules, but they could be perceived to have long-term advantages. In addition, the Congress has order ed the president to report on the possibility of dismantlement. The U.S. and Soviet presidents have both announced plans to dismantle some tactical weapons. ${ }^{1,3}$ Table 1 summarizes the differences in the options.

\subsubsection{Limitation of Attributed Warheads}

Under this scenario, warheads would not actually be counted. Deployed warheads would be accounted for using counting rules that attributed an agreed-upon number of warheads to each type of delivery vehicle. This approach would probably be the easiest to negotiate because it uses the precedent set by START. However, the possibility exists with this scenario that the actual number of deployed warheads on bombers would far exceed the attributed number, because START counts all bombs and SRAMs on a bornber as only one warhead. ALCMs are also discounted. There is no restriction on the number or location of nondeployed warheads. It is possible that delivery vehicles downloaded to carry less than

TABLE 1 Warhead Limitation Options

\begin{tabular}{llllll}
\hline \multicolumn{1}{c}{ Option } & $\begin{array}{l}\text { Warhead } \\
\text { Accounting } \\
\text { Accuracy }\end{array}$ & $\begin{array}{l}\text { Bomber Weapon } \\
\text { Accounting }\end{array}$ & Verification & $\begin{array}{c}\text { Bomber } \\
\text { Loophole }\end{array}$ & $\begin{array}{l}\text { Warhead } \\
\text { Stockpile }\end{array}$ \\
\hline $\begin{array}{l}\text { Limitation of } \\
\text { Attributed WHs }\end{array}$ & $\begin{array}{l}\text { Accurate for } \\
\text { deployed } \\
\text { ballistic } \\
\text { missile WHs }\end{array}$ & $\begin{array}{l}\text { Accounted with } \\
\text { counting rules }\end{array}$ & $\begin{array}{l}\text { Straight- } \\
\text { forward }\end{array}$ & Yes & Large \\
$\begin{array}{l}\text { Limitition of } \\
\text { WHs Actually }\end{array}$ & $\begin{array}{l}\text { Accurate for } \\
\text { deployed } \\
\text { ballistic } \\
\text { missile WHs }\end{array}$ & $\begin{array}{l}\text { Counted or } \\
\text { maximum load } \\
\text { used }\end{array}$ & $\begin{array}{l}\text { More } \\
\text { intrusive }\end{array}$ & None & Large \\
$\begin{array}{l}\text { Limitation of } \\
\text { Tutitl Strategic } \\
\text { WH Arsenal }\end{array}$ & $\begin{array}{l}\text { Accurate for } \\
\text { all WHs }\end{array}$ & $\begin{array}{l}\text { Counted or } \\
\text { maximum load } \\
\text { used }\end{array}$ & $\begin{array}{l}\text { Very } \\
\text { difficult and } \\
\text { intrusive }\end{array}$ & None & Limited \\
\hline
\end{tabular}


their maximum loads could be clandestinely reloaded, leading to fears of breakout." The potential strategic advantage of such noncompliance would have to be perceived as much greater than the consequences of being caught, but this may be a real threat. Frequent inspections could make clandestine reloading less likely to go unnoticed. In addition, START limits on downloading minimize the potential for uploading ballistic missiles.

\subsubsection{Limitation of Warheads Actually Deployed}

It is a common view in the United States and in the Soviet Union that, under START II, "the gap between countable and actual warheads - a source of mistrust built into START I - should be bridged as much as possible." ${ }^{11}$ This scenario requires bomber warhead counting, unless all bombers are fully loaded, because accounting for warheads using counting rules could over- or undercount. Under this scenario, too, there is the possibility of large numbers of uncounted, nondeployed warheads, which could lead to serious fears of breakout. However, the so-called "bomber loophole" is eliminated.

\subsubsection{Limitation of the Total Number of Warheads}

Limiting the nuclear arsenal, perhaps as a move toward the idealistic goal of eliminating all nuclear weapons, could be accomplished by declaring and verifying the total stockpiles of both parties. Excess warheads would be disabled or dismantled. B/th the U.S. and the Soviet Union are formally committed to working toward the elimination of all weapons of mass destruction. ${ }^{\dagger 23}$ A Soviet arms control counselor wrote recently, "for both political and military reasons, it is extremely important that in START II the two sides proceed to actual disarmament, that is, a controlled elinination of nuclear warheads." In the United States, some members of both houses of Congress support dismantlement. The House Armed Services Committee's version of the 1991 military budget bill urged the president to enter negotiations on dismantlement and fissile-material cutoff, and it required a report by April $30,1991 .{ }^{\ddagger}$ The Senate bill was similar. ${ }^{25}$ President Gorbachev has recently requested a cutoff: "We also want to agree with the United States on a controllable cessation of the production of all fissionable materials wbich are used for the manufacture of weapons. ${ }^{13}$

\footnotetext{
*"Breakout" is the situation in which one treaty party in time of crisis rapidly deploys more weapons. than permitted by treaty.

'See, for example, the Biological Weapons Convention (Ref. 23), which begins, "The States Parties..., determined to act with a view to achieving effective progress towards general and cumplete disarmament, including the prohibition and elimination of all types of weapons of mass destruction....". See also the Limited Test Ban Treaty (LTBT), Non-Proliferation Treaty (NPT), Anti-Ballistic Missile ( $\mathrm{ABM}$ ), and Strategic Arm.s Limitation Treaty II (SALT II) treaties.

The U.S. Department of Energy (DOE) has submitted a lengthy detailed report to the president; the report is classified, but its executive summary (Ref. 24 ) is publicly available.
} 
However, dismantlement does not necessarily enhance stability. The important thing is to remove from operation one element of the strategic weapons delivery system, and delivery vehicles are rather easy to verify and eliminate. "A ballistic missile warhead has very limited military utility without a ballistic missile to carry it to a target. From this viewpoint, a limit on the total inventory of missiles accomplishes very nearly the same thing as a limit on the total inventory of warheads, that is, it achieves real reductions and limits damage if war occurs." 13 There may be environmental, health, safety, and economic reasons for dismantlement, but these are separate issues that should not be used to further encumber a treaty that will be difficult enough to negotiate without them. Unilateral dismantlement of excess weapons and a production cutoff could be undertaken without a treaty, without affecting the U.S. strategic deterrent force, because materials sufficient to meet our needs could still be retained. Dismantlement of some U.S. and Soviet tactical nuclear weapons is now plianned. ${ }^{1,3}$

If nondeployed warheads are not limited, there is the possible concern of breakout, either by uploading declarer! deployed SNDVs that have been downloaded, or by loading and deploying (covert or declared) nondeployed SNDVs. The possibility of uploading has been limited under START by limiting downloading. The brsinuui concern can be reduced further by limiting the numbers of warheads stored near deployment hases, by monitoring transport to bases, and by on-site inspections.

Verification of a limit on all warheads could be very intrusive and difficult (see Section 4.2.3).

\subsubsection{Limits on Warhead Reductions}

If the total number of warheads were to be further reduced, it would be prudent to address the question of reasonable lower limits. The idealistic goal of entirely ridding the world of nuclear weapons may not be achievable in the foreseeable future; the genie is out of the bottle. To determine realistic lower limits, not only must we consider stability and political relations between the U.S. and the Soviet Union at very low arms levels, but we also must recognize the possibility of some day reaching a point where other nuclear nations' arsenals could be a factor (especially that of China, but also those of France, Great Britain, and others). These other nuclear nations must eventually be brought into the picture. It is worth considering what conditions would define that point, and whether anything being considered now could eventually lead to stumbling blocks in such a multilateral context.

It has been suggested that START II should be multilateral. Paul Nitze, for example, believes that other nations should be brought into the picture at levels below 5000 weapons for each of the superpowers. ${ }^{14}$ This might serve to maintain the relative positions of the superpowers to other nuclear powers. The latter powers, however, may not choose to enter negotiations until the superpower arsenals are reduced to hundreds rather than thousands of warheads. Great Britain would require that U.S. and Soviet arsenals he reduced far below START limits, and France would consider entering into strategic arms negotiations when the U.S. and Soviet nuclear capabilities were reduced to a level 
comparable with their own (now about 350 warheads). ${ }^{26}$ The time for multilateral involvement may be approaching faster than had previously been anticipated. The Fincucial Times recently reported, "Mr. Bush's far-reaching proposals also imply that London and Paris are approaching the moment when they have to review their own nuclear defense policies and participate in the nuclear arms control process." 27 


\section{RESULTING U.S. FORCE STRUCTURE}

\subsection{GENERAL DISCUSSION}

The desired force structure under both START and START II must have what has been termed "structural stability" - that is, changes in the world political environment must. not be able to put the United States at a disadvantage. In addition, either treaty would lead to changes in the SIOP. As Paul Warnke (former ACDA director), reminds us, "the SIOP drives everything. Unless the SIOP changes, nothing else changes." 14 The basic policy driving the SIOP is set by the president in a National Security Decision Directive (NSDD), currently NSDD-13, and in a guide to nuclear weapons employment policy (NUWEP-87). The ISTPS does the actual detailed targeting. ${ }^{*}$

\subsubsection{Target Base}

The target base under START II could be considerably reduced from its current dimensions. First, the Soviets will be reducing their strategic arsenals as we do to comply with START, and then START II, and reducing their conventional arms under the Conventional Forces in Europe (CFE) treaty. Second, if the Soviets continued moving tow c rds mobile systems, bases would be targeted instead of individual weapons. Third, the geographical area of the target base is itself shrinking due to dramatic political changes. It no longer makes sense to target Eastern Europe or the Baltic republics, and any targets there are presumably being eliminated from the target base as Soviet forces are withdrawn. Fourth, "significant numbers of conventional forces and facilities... are being demobilized, and major war-supporting industrial plants are being converted to production of consumer goods."

In addition, the remaining target base should be continually examined to remove any inconsequential or inappropriate targets and to determine whether lower damage expectancies would be acceptable for any remaining target classes. It may not make sense to demand a high certainty that every Soviet system will be damaged. Stanford professor Scott Sagan contends that hitting even a fraction of the current base of about 14,000 targets "would cause the Soviet Union to cease to be a functioning society." 14 One military official has said, "I cannot imagine that any rational review of the target list would lead one to the conclusion that we've got about the right number of targets. It's got to tell you that there's a lot of targets that we don't need to go after." 28

A more detailed examination of the target base needs to be included in future work.

\footnotetext{
"In theory, the guiding hand is the president's, so that decisions based on arms control can be implemented. In practice, however, the process may resemble the game of "telephone," with each player in the chain interpreting the message in his own way, so that the end product may not be exactly what the president had in mind.
} 


\subsubsection{Targeting Doctrine}

Our basıc targeting doctrine merits review. Congressman Les Aspin, Chairman of the House Armed Services Committee, was quoted as saying that "our entire targeting doctrine needs to be rethought in light of START reductions." 29 Senator Sam Nunn also proposed a review of targeting doctrine. ${ }^{14}$ Although there was a recent review, the changing relationship of the United States and the Soviet Union could make further review appropriate. A change in policy from complete coverage of the target base to a credible retaliatory threat of "unacceptable damage" would leave us a substantial target base, but the number of weapors required would be considerably reduced. Unacceptable damage has been defined as destroying at least one-fifth of the Soviet population and one-half of Soviet industry. Even this level of damage seems excessive in today's world. Robert McNamara calculated that such damage would require 400 one-megaton weapons. The current version of the SIOP is reported to allocate over 12,000 warheads to Soviet targets. ${ }^{30}$

Severe restrictions on number of warheads under START II will likely make complete coverage of an extensive target set impossible. It will, therefore, be necessary to choose an appropriate set from among potential targets. One author has considered removing from the target set both targets that are too hard to find (e.g., mobiles) or too difficult to destroy (e.g., very hard targets) and silos, which would presumably be empty at the time of a retaliatory strike anyway. ${ }^{31}$ Implications of such a major change in targeting policy for crisis stability can be included in future studies.

\subsubsection{Scenario Development}

With the knowledge in mind that the number of targets and the weapons needed to cover them could be reduced drastically, this section identifies U.S. weapon systems available, recognizing any that are essential for coverage of specific target classes, and examines possible force structures under START II using these systems. The analysis takes as its starting point force levels defined by S'TART (1600 SNDVs, etc.). The actual U.S. postSTAR'T force structure will, of course, be determined by the JCS and will include roles for both Air Force and Navy systems, although they will be under a single command. ${ }^{1}$ Detailed examination of weapon allocation to the actual target base, for the U.S. and Soviet Union, could be included in future work.

Several possible (extreme) post-START II force structures are considered here. These are maximum land-based missiles, maximum submarine-based missiles, and elimination of fixed MIRVed systems, which is a variant on the first two structures. Only U.S. force structures are addressed here; similar work is proposed for Soviet forces. The analysis also identifies potential problems for the U.S. (and, potentially, for the Soviets) in coping with the postulated limits. 


\subsection{ELEMENTS OF U.S. FORCES}

U.S. strategic forces current at the date of START signature (July 31, 1991) are listed in Table 2 and examined in Figure 1. ${ }^{32,33}$ Approximately half of the B-52 bombers are no longer active and will be eliminated under START. Note that current delivery vehicles are rather evenly distributed among types, but SLBMs make up almost half of accounted warheads, while bomber weapons make up almost half of actual warheads.

\subsubsection{ICBMs}

\subsubsection{Silo-Based Missiles}

The United States currently has 1000 silo-based ICBMs. There are $50 \mathrm{MX}$ or "Peacekeeper" missiles, first deployed around 1986, with the remainder a mix of older, singlewarhead Minuteman IIs and Minuteman IIIs having three warheads. As a general rule, it is assumed that military planners will be more reluctant to give up their newer, higherperformance systems under arms control agreements than older ones. Some phasing out of the Minuteman (MM) is therefore assumed under all scenarios, with the extreme case involving total elimination. Elimination of the MM II is planned under START. However, there is no urgency in phasing out the MM III. "The Minuteman force has been very effective and can stay effective for a long time."10 Under some force structures examined, MX missiles could have been removed from silos and deployed on railcars, although that option is now impossible. The MX is considered mobile under START. Elimination of the MXs, perhaps as part of an exchange for Soviet SS-18s, is also considered as a possibility.

Our ICBMs are generally assigned missions that require prompt hard-target kill capabilities. Current strategy "requires weapons that are quick and accurate. They must be launched rapidly to escape a surprise attack ... [A]nd they must be accurate enough to destroy fortified, or 'hardened,' Soviet military installations."

Two interesting arguments have been proposed to justify considering silo-based missiles as survivable. The first reasons that no adversary would attack U.S. land-based missiles, because the other two legs of the Triad are survivabla; therefore the land-based missiles are survivable. ${ }^{5}$ The second considers that silo-based missiles are survivable because they can be launched on warning. ${ }^{34}$ Neither of these arguments is consistent with the operative definition of survivability - the ability to ride out an attack. Silo-based missiles

are vulnerable to a first strike and, therefore, are not considered to be survivable. As Paul Nitze stated recently, "These missiles [ICBMs with multiple warheads], which are both vulnerable to attack and highly attractive as targets, provide each side with an incentive to strike the other first and furce both to take dangerous counter measures to protect these weapons. Their mutual elimination would therefore strengthen both deterrence and safety." 15 
TABLE 2 U.S. Strategic Force Structure at START Signature ${ }^{a}$

\begin{tabular}{|c|c|c|c|}
\hline \multirow[b]{2}{*}{ System } & \multicolumn{2}{|c|}{1991 Forces } & \multirow[b]{2}{*}{$\begin{array}{l}\text { Actual } \\
\text { WHs }\end{array}$} \\
\hline & SNDVs & $\begin{array}{l}\text { Accounted } \\
\text { WHs }\end{array}$ & \\
\hline \multicolumn{4}{|l|}{ ICBMs } \\
\hline MM II & 450 & 450 & 450 \\
\hline MM III & 500 & 1500 & 1500 \\
\hline $\mathrm{MX}$ & 50 & 500 & 500 \\
\hline Midgetman & 0 & 0 & 0 \\
\hline Subtotal & 1000 & 2450 & 2450 \\
\hline \multicolumn{4}{|l|}{$\sim r_{3} \mathrm{Ms}$} \\
\hline $\begin{array}{l}\text { Poseidon [C3] } \\
16 \text { per Poseidon sub }\end{array}$ & $192 / 12$ & 1920 & 1920 \\
\hline $\begin{array}{l}\text { Trident I [C4] } \\
16 \text { per Poseidon sub }\end{array}$ & $240 / 15$ & 1920 & 1920 \\
\hline $\begin{array}{l}\text { Trident I }[\mathrm{C} 4]_{i} \\
24 \text { per Trident sub }\end{array}$ & $144 / 6$ & 1152 & 1152 \\
\hline $\begin{array}{l}\text { Trident II [D5] } \\
24 \text { per Trident, sub }\end{array}$ & $72 / 3$ & 576 & 576 \\
\hline Subtotal & $648 / 36$ & 5568 & 5568 \\
\hline Ballistic missile subtotal & 1648 & 8018 & 8018 \\
\hline \multicolumn{4}{|l|}{ Bombers } \\
\hline $\begin{array}{l}\text { B-52 } \\
\text { bomb/SRAM }\end{array}$ & & & \\
\hline ALCM & $\begin{array}{l}290 \\
189\end{array}$ & 290 & $3480^{\mathrm{h}}$ \\
\hline Total & $\begin{array}{l}189 \\
479\end{array}$ & $\begin{array}{l}1968 \\
2258\end{array}$ & $\begin{array}{l}3028 \\
6508\end{array}$ \\
\hline B-2 & 0 & 0 & 0 \\
\hline Bomber subtotal & 574 & 2353 & 8028 \\
\hline Total & 2222 & 10371 & 16046 \\
\hline
\end{tabular}

"Source: Ref. 32, with detailed B-52 data estimated.

h Typical load of 12 used (see Ref. 33).

\subsubsection{Mobile Missiles}

Mobile land-based missiles are survivable if appropriately based and properly operated, whether MIRVed or not, and are, therefore, an acceptable part of a force mix. 'The United States's decision whether to deploy mobile ICBMs should have been based on their perceived role in fulfilling necessary missions not covered by other survivable systems. Tho. recent decision to terminate both mobile programs was probably based on political and 

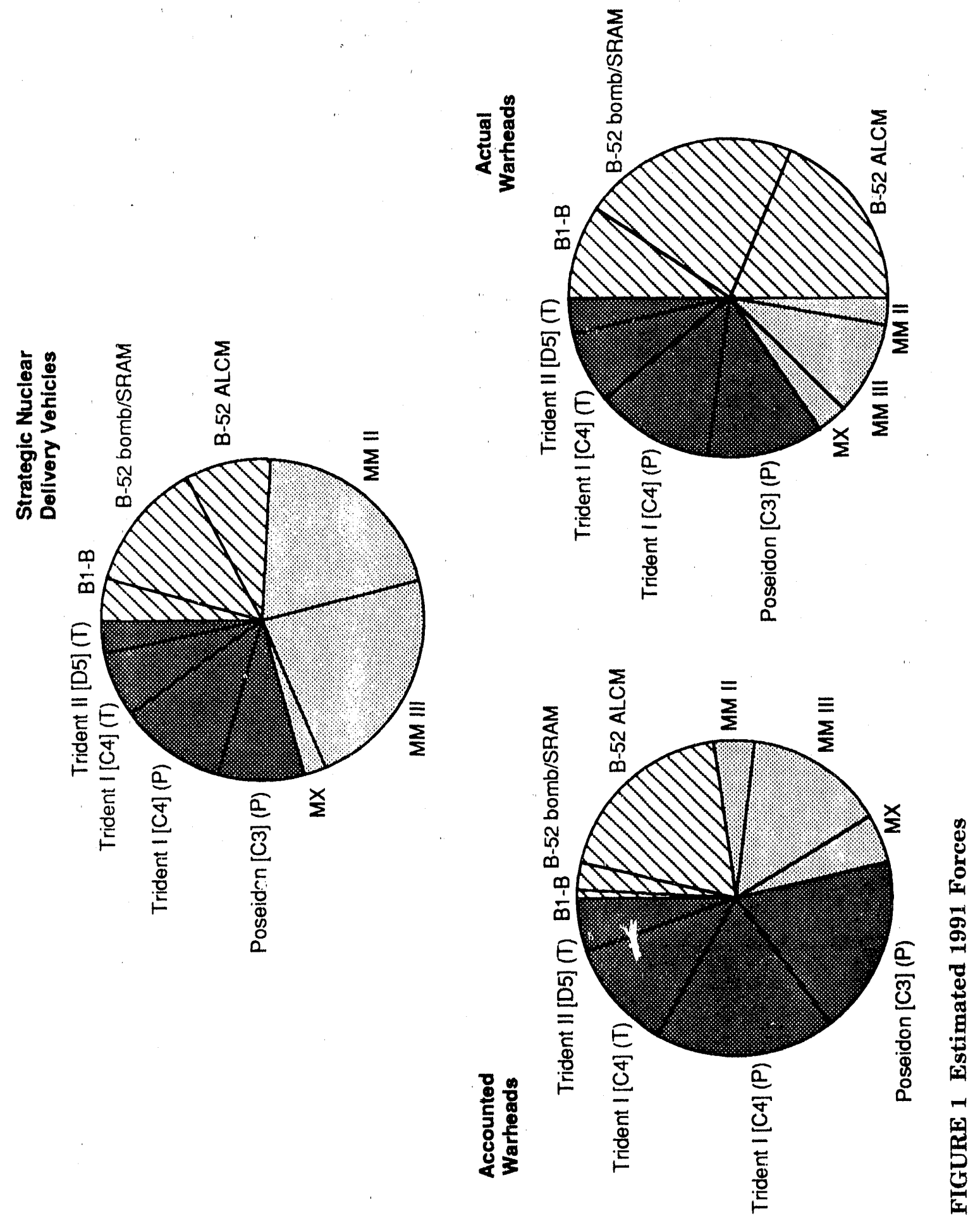
financial considerations, but the systems did not have unique missions. Congress would have been reluctant to fund any mobile missiles in the current world climate; President Bush knew this. Certain unavoidable asymmetries exist between the U.S. and USSR, especially in torms of geography and political realities. Therefore, the most appropriate systems for the Sovicts are not necessarily the most appropriate for the U.S. The U.S. does not need to match tho Suviets weapon for weapon, so long as all credible missions are covered. The Sovists maty favor mobile ICBMs, while the U.S. may choose to rely more heavily on submarines, especially if the U.S. cannot operate mobile ICBMs in a survivable mode. (For further discussion, see Ref. 36.)

The maximum U.S. mobile missile force considered here included 250 missiles, with 700 WHs (50 rail-mobile MXs with 10 WHs and 200 Midgetman missiles with 1 WH each), as SAC proposed under START (see Table 3) (Ref. 37). This was the upper bound on possible U.S. mobile missiles, with zero as the lower bound.

\subsubsection{Submarines}

Funds have already been committed for construction of 18 Trident submarines. This number is, therefore, the lower bound of deployed submarines included in possible force structures under START. The possibility of having as many as 24 submarines was examined but found to be unlikely, both because of an over-reliance on submarines under such force structures and because of the current funding situation. Aging Poseidon submarines are assumed to be phased out, but options are considered for retaining a small number until START II reductions are begun. The base-case assumption is that the submarines will be fully loaded, but options for deploying greater numbers of submarines, each with fewer missiles or warheads on board, are also included.

Poseidon submarines carry 16 missiles each, either the older C-3 (Poseidon) missiles with 10 warheads each, or the newer C-4 (Trident I) missiles with eight WHs each. 'Trident submarines can each carry 24 missiles, either the C-4 or the newly deployed D-5 (Trident II), each with eight warheads. It is assumed that SLBMs are capable of carrying out all of the missions previously reserved for the MX, because of the increased accuracy and yield available with the D-5. "Technically, the D-5 missile on Trident submarines is sufficiently

accurate to provide this [prompt] hard-target capacity."6 Future work will detcrmine if enough D-5s can be deployed to cover all MX missions. A U.S. strategic "Dyad," where SLBMs took on all ICBM missions, would be possible. The merits of a force structure with more or fewer than three elements are the subject of much debate.

\subsubsection{Bombers}

The B-2s for which funds have been appropriated are assumed to be built and deployed as programmed, although there is some argument over their mission. President Bush still supports the B-2 program in spite of funding difficulties in Congress. ${ }^{1} \mathrm{~B}-1 \mathrm{Bs}$ are 
TABLE 3 Possible Force Structures Scenario: SAC Post-START Wish List (maximum land-based missiles)

\begin{tabular}{|c|c|c|c|c|c|c|}
\hline \multirow[b]{2}{*}{ System } & \multicolumn{3}{|c|}{ Post-START ${ }^{\mathrm{a}}$} & \multicolumn{3}{|c|}{ Post-START II } \\
\hline & SNDV & $\begin{array}{l}\text { Accounted } \\
\text { WHs }\end{array}$ & $\begin{array}{l}\text { Actual } \\
\text { WHs }\end{array}$ & SNDVs & $\begin{array}{l}\text { Accounted } \\
\text { WHs }\end{array}$ & $\begin{array}{l}\text { Actual } \\
\text { WHas }\end{array}$ \\
\hline \multicolumn{7}{|l|}{ ICBMs } \\
\hline MM II \& III & 600 & 1097 & 1097 & 50 & 50 & 50 \\
\hline $\mathrm{MX}$ & 50 & 500 & 500 & 50 & 500 & 500 \\
\hline Midyetman & 200 & 200 & 200 & 200 & 200 & 200 \\
\hline Subtintal & 850 & 1797 & 1797 & 300 & 750 & 750 \\
\hline \multicolumn{7}{|l|}{ SLABMs } \\
\hline $\begin{array}{l}\text { Pnseidon } \\
16 \text { per Poscidon sub }\end{array}$ & 0 & 0 & 0 & 0 & 0 & 0 \\
\hline $\begin{array}{l}\text { Trident I } \\
16 \text { per Poseidon sub }\end{array}$ & 0 & 0 & 0 & 0 & 0 & 0 \\
\hline $\begin{array}{l}\text { Trident V/II } \\
24 \text { per Trident sub }\end{array}$ & $378 / 21$ & 3024 & 3024 & $212 / 12$ & 1696 & 1696 \\
\hline Subtintal & 378 & 3024 & 3024 & 212 & 1696 & 1696 \\
\hline Ballistic missile subtotal & 1228 & 4821 & 4821 & 512 & 2446 & 2446 \\
\hline \multicolumn{7}{|l|}{ Bombers } \\
\hline $\mathrm{B} 1 \cdot \mathrm{B}$ & 95 & 95 & 1.520 & 95 & $\begin{array}{l}\text { ALCM, } 350 \\
\text { other, } 60\end{array}$ & $\begin{array}{l}700 \\
960\end{array}$ \\
\hline \multicolumn{7}{|l|}{ B-52 } \\
\hline bomb/SRAM & 0 & 0 & 0 & 0 & 0 & 0 \\
\hline ALCM & 95 & 950 & 1900 & 0 & 0 & 0 \\
\hline$B-2$ & 132 & 132 & 2112 & 132 & 132 & 2112 \\
\hline Bomber subtotal & 322 & 1177 & 5532 & 227 & 542 & 3772 \\
\hline Totial & 1550 & 5998 & 10353 & 739 & 2988 & 6218 \\
\hline
\end{tabular}

"Source (post-START only): Ref. 37.

h If fully loaded. Note incomplete loading of larger number of submarines than currently expected under this scenario.

assumed to be kept throughout the study period, either loaded with gravity bombs and SRAMs as they now are, or possibly converted to carry ALCMs if a substantial number of B-2s are built. Some phasing out of B-52s is assumed as any B-2s are brought into service, but the possibility of keeping the B-52s operational is also considered.

Bombers are slow fliers, compared with missiles; therefore, bombers are not assigned any prompt missions under the SIOP. This is the reason that they are viewed as less threatening than missiles and their weapons discounted under START'. 


\subsection{POSSIBLE U.S. FORCE STRUCTURE SCENARIOS}

Several scenarios are considered to provide bounds on the likoly number's of itoms doployed in each category under START and then under START 11. It is expected that realistic planning would develop a scenario somewhere between these bounds. Examination of these extreme scenarios provides insight concerning those possible treaty limits that. would most constrain U.S. military planners. In most cases, types of systems are considered ( $\theta . \mathrm{g}$., bombers) for this general study, rather than specific systems (e.g., B-2s). Other factor's, such as costs, capabilities and missions, and the national and world political situations, will influence actual choices of which systems to deploy.

The two basic scenarios are based on (1) maximizing the number of missiles deployed on land under the two treaties and (2) maximizing the number deployed on submarines. Variations in the numbers and types of bombers (ALCM vs bomb/SRAM) are also considered. A third scenario, based on the elimination of fixed MIRVed systems, now the most likely possibility, is also examined.

\subsubsection{Maximum Land-Based Missiles}

\subsubsection{START}

This scenario was based on a post-START force structure postulated by the Strategic Air Command (see Table 3). ${ }^{37}$ It presumably represented the SAC's wish list, and as such it was the upper bound on systems they could realistically have been expected to deploy. Included were $50 \mathrm{MX}$ missiles (possibly rail-mobile) and 200 Midgetman missiles (presumably road-mobile), as well as 132 B-2 bombers (variants with fewer B-2s, including less than the 75 now requested, are much more likely). This scenario is now very unlikely, because the two mobile programs have been killed. It is still included for comparison. Because compliance with treaty limits is expected, the maximum ICBM scenario also corresponds to minimum missiles on submarines.

This proposed force structure can be seen to comply neatly with all START limits and sublimits (including the 3300-SLBM warhead sublimit the Soviets had proposed). The submarine force is assumed to include 21 submarines (three more than we are committed to build), each with 18 tubes loaded with eight-warhead SLBMs. Although this is assumed to be accomplished by incomplete loading of the 24-tube Trident submarines, it could also be accomplished with fewer fully loaded Trident submarines or with a mix of Tridents and Poseidons. The same result could also be achieved by loading some of the SLBMs with fewer than eight warheads, but this could violate the START downloading limits. Incomplete loadings complicate, but do not prevent, vcrification, as is discussed in Section 4.

The postulated force structure includes a mix of Minuteman II and partially deMIRVed Minuteman III missiles, for a total of just under 1800 ballistic missile warheads (well below the 3300 ICBM WH sublimit the U.S. had proposed). The force mix also includes 
322 bombers, 95 of which are B-52s carrying ALCMs, The remaining 227 are B-1B and B-2 bumbers carrying nuclear gravity bombs and SRAMs; each of these is counted for one warhead each under START counting rules, even though artual loadings are likely to be considerably higher. These extra warheads constitute what has been called the "bomber loophole," and this scenario takes maximum advantage of the loophole, with 3400 legal but uncounted bombs or SRAMs possible (in addition to the 950 discounted ALCMs). The utility of these warheads would depend on the missions assumed for the bombers and on the utility perceived for missions carried out after an initial nuclear exchange.

\subsubsection{START II}

What would be the force structure under START II after a maximum land-based missile force structure under START? The most obvious answer is that we would keep as many of the new systems as we could. This path, however, would place very serious constraints on submarines under the postulated START II provisions, Since this is a maximum land-based missile scenario, we first assume that the 50 MXs and 200 Midgetmen are retained, along with the maximum $132 \mathrm{~B}-2 \mathrm{~s}$. For now, we also assume that all but 50 single-warhead Minutemen and all B-52s are phased out by the time START II reductions are achieved. (Not making this last assumption either puts even tighter constraints on submarines or leads to reduced numbers of B-2s, which is a likely possibility but is equivalent to the crase being considered, in terms of structural impacts.)

If all B-52/s were phased out, some B1-Bs would probably be modified to carry ALCMs. The minimum number of submarines would occur under this scenario if all B1-Bs became ALCM carriers. In this case, in order to stay under the 3000-warhead limit, there could only be 1144 warheads on SLBMs, equivalent to six fully loaded submarines or 12 halfloaded submarines. It is unlikely that military strategic planners would consider this sufficient. Therefore, we consider a slight cutback in SAC's systems. The modification involves assuming the same SAC platforms are retained, but fewer ALCM-capable B-1Bs. Then the maximum number of SLBM warheads that would still allow compliance with the assumed 2450 sublimit on ballistic missile warheads is 1700 , equivalent to $1275 \%$-loaded submarines. (Even this number slightly exceeds the 1650-SLBM-warhead sublimit that would have resulted from accepting a 3300 sublimit under START and halving it under START II.) The 3000-warhead limit would still allow for 35 ALCM-carrying B-1Bs. This force structure is indicated in Table 3.

If START counting rules are retained, the 192 non-ALCM bombers could carry about 2600 legal uncounted warheads, almost as many as before the START II reductions, and a number comparable with the number of counted warheads. Careful consideration should be given to whether closing this "bomber loophole," which could be proportionately larger under" START II than under START, is advantageous or not. 


\subsubsection{Maximum Submarine-Based Missilos}

\subsubsection{STAR'T}

At the other extreme from the case of maximum landabasod missiles is tho case

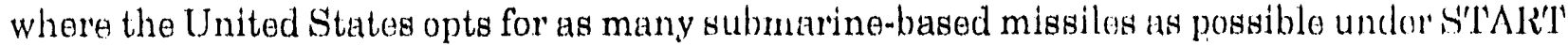
and then again under START II. The force structure for this scenario is indicated in 'Table 4. Since the total of SLBM and ICBM warheads is limited (to 4900 under STAL'T, and postulated at half that for S'TART II), the maximum number of submarine-based missiles corresponds to the minimum of land-based missiles. We assume here that the U.S. chooses to keep the MX initially, because it is a new system, but eliminates all of the vlder Minuteman missiles. The decision not to make the MX mobile has now been made, but it did not directly affect the discussion of numerical constraints under strategic arms agreements. No Midgetman missiles are included in this scenario.

If the 500 warheads on 50 MX missiles are the only ICBM warheads, then S'I' $\triangle R$ 'T"s 4900 ballistic missile warhead sublimit would permit 4400 SLBM warheads $(550$ missiles with eight warheads each, much more than the 3300 sublimit on SIABM warheads that the Soviets had proposed). The 4400 SLBM warheads are approximately equivalent to the 18 Trident submarines, with 24 fully loaded missile tubes each, that the U.S. is committod to build, plus eight existing Poseidon submarines, each with almost all 16 tubes loaded. Additional Tridents could be required if the Poseidons could not be kept operating until START II reductions began. One plan would have allowed threo additional submarines in refit that would not be counted, but this plan was dropped.

Most of the remaining 1100 warheads to be deployed on bombers could be placed (m the 95 B-1Bs (carrying nuclear gravity bombs and/or SRAMs) and 95 ALCM-carrying B-52s, as in SAC's plan (discussed above), with the rest of the warheads on about 60 additionil bombers (bombs/SRAMs). These additional bombers would presumably include the $1513.2 \mathrm{~s}$ to which the U.S. is committed, but more B-52s could be retainod if they (or B1-Bs) wore judged capable of accomplishing whatever mission is devised for the B-2. Over 2000) uncounted bombs/SRAMs could be deployed, as well as 950 discounted ALCMs.

The maximum submarine-based missiles scenario is tightly warhead-constrained: the force structure includes the maximum allowed warheads, but only about 850 of the alluwed 1600 delivery vehicles. This means that it is a highly MIRVed force, but it is still highly survivable. The maximum land-based missiles scenario included over 1500 SNI)Vs and was therefore less highly MIRVed (see Table 5). However, the 600 fixed land-hased missiles in that scenario are vulnerable to a first strike, and the survivability of the mobile missiles depends on their basing modes. In this case, the more MIRVed structure appears to be more stabilizing. The goal of deMIRVing per se should, therefore, be examined. The two extreme scenarios are compared graphically in Figure 2. 
TABLE 4 Possible Force Structures Scenario: Maximum Submarine-Based Missiles

\begin{tabular}{|c|c|c|c|c|c|c|}
\hline \multirow[b]{2}{*}{ System } & \multicolumn{3}{|c|}{ Post-START } & \multicolumn{3}{|c|}{ Post-START II } \\
\hline & SNDVs & $\begin{array}{l}\text { Accounted } \\
\text { WHs }\end{array}$ & $\begin{array}{l}\text { Actua! } \\
\text { WHs }\end{array}$ & SNDVs & $\begin{array}{l}\text { Accounted } \\
\text { WHs }\end{array}$ & $\begin{array}{l}\text { Actual } \\
\text { WHs }\end{array}$ \\
\hline \multicolumn{7}{|l|}{ ICBMs } \\
\hline MM II \& III & 0 & 0 & 0 & 0 & 0 & 0 \\
\hline $\mathrm{MX}$ & 50 & 500 & 500 & 10 & 100 & 100 \\
\hline Midgetman & 0 & 0 & 0 & 0 & 0 & 0 \\
\hline Subtutal & 50 & 500 & 500 & 10 & 100 & 100 \\
\hline \multicolumn{7}{|l|}{ SLBMS } \\
\hline Poseidon & 0 & 0 & 0 & 0 & 0 & 0 \\
\hline $\begin{array}{l}\text { Trident I } \\
16 \text { per }\end{array}$ & $192 / 12$ & 1536 & 1536 & 0 & 0 & 0 \\
\hline $\begin{array}{l}\text { Poseidon sub } \\
\text { Trident I/II } \\
24 \text { per } \\
\text { Trident sub }\end{array}$ & $358 / 15$ & 2864 & 2864 & $288 / 12$ & 2304 & 2304 \\
\hline Subtutal & 550 & 4400 & 4400 & 288 & 2304 & 2304 \\
\hline $\begin{array}{l}\text { Ballictic missile } \\
\text { subtotal }\end{array}$ & 600 & 4900 & $49 \cap 0$ & 298 & 2404 & 2404 \\
\hline \multicolumn{7}{|l|}{ Bumbers } \\
\hline B1-B & 95 & 95 & 1520 & 95 & $\begin{array}{l}\text { ALCM, } 350 \\
\text { other, } 60\end{array}$ & $\begin{array}{l}700 \\
960\end{array}$ \\
\hline \multicolumn{7}{|l|}{$B-52$} \\
\hline bo $\mathrm{mb} / \mathrm{SRAM}$ & 38 & 38 & 456 & 38 & 38 & 456 \\
\hline ALCM & 95 & 950 & 1900 & 13 & 130 & 260 \\
\hline$B \cdot 2$ & 15 & 15 & 240 & 15 & 15 & 240 \\
\hline Bomber subtotal & 243 & 1100 & 4116 & 161 & 593 & 2616 \\
\hline Total & 843 & 5998 & 9016 & 459 & 2997 & 5020 \\
\hline
\end{tabular}

\subsubsection{STAF' II}

Taking the maximum SLBM scenario to START II, we assume that 10 MX missiles would be retained to maintain the Triad (we consider phasing them out entirely under the third scenario). Alternatively, the U.S. could maintain a small number of single-warhead ICBMs. This would allow 2350 SLBM warheads, or 12 fully loaded Tridents. Thus, it is clear that postulating the timely negotiation of START II allows even the most submarinedependent force structure to be achieved with the vessels already in the pipeline, as long as somo of the older Poseidon submarines can be kept operating until START II reductions bexin. However, if START II were delayed and the Poseidons required replacement, additional submarines could eventually be needed. In addition, if military strategists in the future yudged that anti-submarine warfare (ASW) breakthroughs were likely, it might then 
TABLE 5 Comparison of Extreme Force Structures under START and START II

\begin{tabular}{|c|c|c|c|c|c|}
\hline \multirow[b]{2}{*}{ Item } & \multirow{2}{*}{$\begin{array}{c}\text { Current } \\
\text { Forces, } \\
1991 \\
\end{array}$} & \multicolumn{2}{|c|}{$\begin{array}{c}\text { Maximum } \\
\text { Land-Based } \\
\text { Missiles }\end{array}$} & \multicolumn{2}{|c|}{$\begin{array}{c}\text { Maximum } \\
\begin{array}{c}\text { Submarine-Based } \\
\text { Missiles }\end{array} \\
\end{array}$} \\
\hline & & $\begin{array}{l}\text { Post- } \\
\text { START }\end{array}$ & $\begin{array}{l}\text { Post- } \\
\text { START II }\end{array}$ & $\begin{array}{l}\text { Post- } \\
\text { START }\end{array}$ & $\begin{array}{l}\text { Post- } \\
\text { START II }\end{array}$ \\
\hline $\begin{array}{l}\text { MIRVing (ratio of } \\
\text { missile warheads } \\
\text { to SNDVs) }\end{array}$ & 5.1 & 3.9 & 4.8 & 8.2 & 8.1 \\
\hline $\begin{array}{l}\text { Ratio of actual to } \\
\text { counted warheads }\end{array}$ & 1.55 & 1.73 & 2.8 & 1.50 & 1.68 \\
\hline
\end{tabular}

be decided to spread U.S. missiles on more platforms, either by deploying additional but incompletely loaded Tridents or by building a smaller submarine.

The remaining bomber forces could be deployed on the $95 \mathrm{~B}-1 \mathrm{Bs}$, plus abuut 50 bombers with gravity bombs and/or SRAMs. Again, these bombers would include whatever B-2s are judged necessary, and some of the B-1Bs could be refitted to carry ALCMs. ONen 1:300 uncounted hombs/SRAMs could be deployed.

\subsubsection{Elimination of Silo-Based Multiple-Warhead Missiles}

Under the third scenario, it is postulated that the U.S. and the Soviet Union agree to eliminate all fixed MIRVed missiles under START II. This could result from a trade including the MX and the SS-18, which has become more likely. The result would be at rathel' considerable improvement in stability. Variants on this scenario can be constructed from both the maximum land-based missiles and maximum submarine-based missiles sconarios.

Under the maximum land-based missiles scenario, all 50 currently deployved MX missiles would have remained after START II limits were accomplished. If, however, the MX were to be eliminated, as now seems likely, the 500 warheads carried could be carricd on another delivery vehicle. The most obvious thing to do would be to put them on additional single-warhead missiles (say, the Midgetman). This would serve to compensate the Air Force for the loss of the MX system. However, this creates more targets, and anything ovir a 60-missile increase over the postulated maximum land-based missiles scenario violates the postulated $800-$ SNDV limit. One reasonable possibility would be to reject this limit as not contributing to stability and allow additional missiles until the warhead limits were reached. A less attractive possibility would be to put the remaining warheads on additional $A I C M$ carrying bombers. However, this possibility would lead to a force structure with fewer. ballistic-missile warheads than the START II sublimit allows, and this situation could he perceived as a reduction in prompt retaliatury capability. 

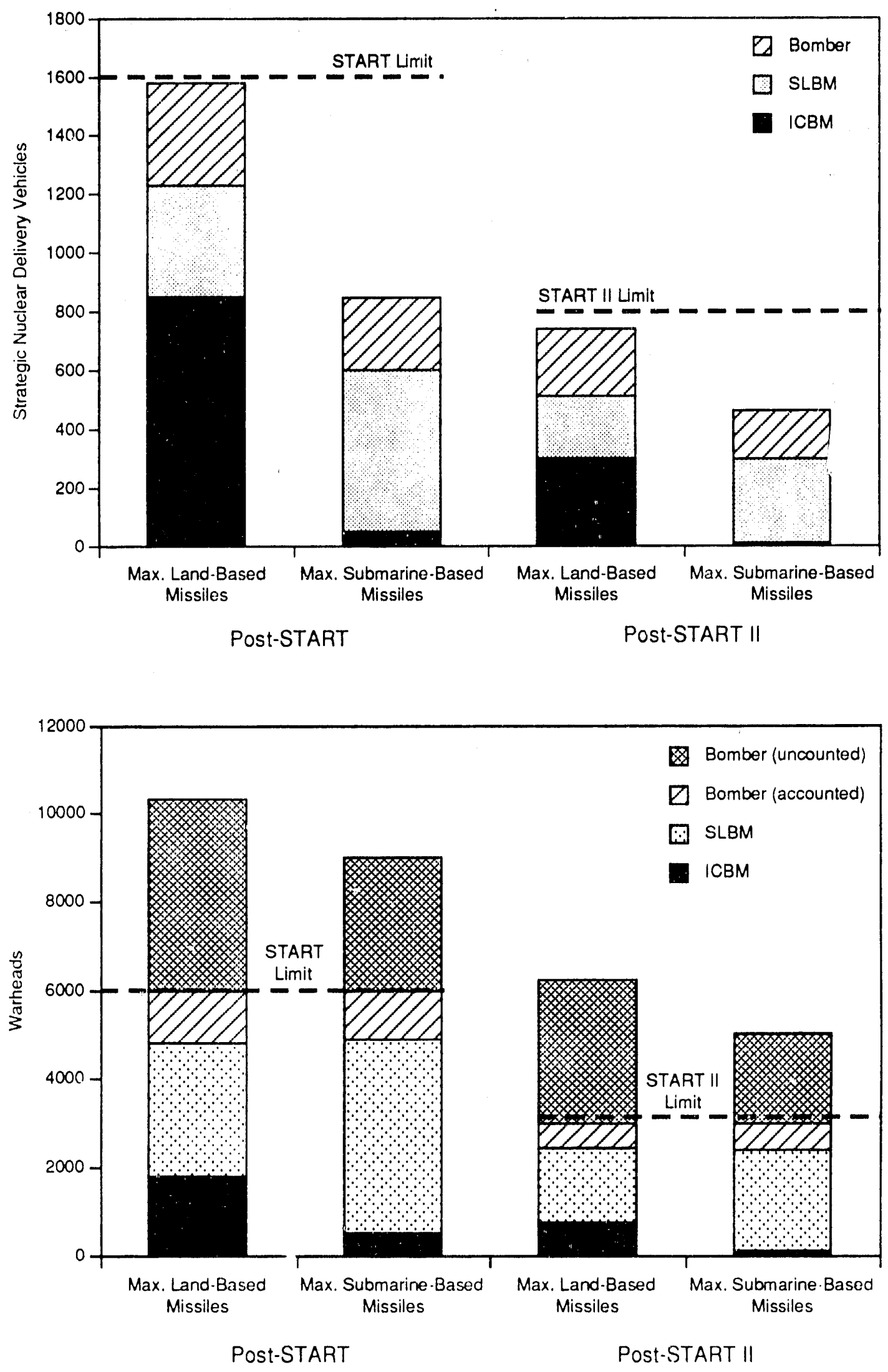

FIGURE 2 Comparison of Extreme Force Structures 
The maximum submarine-based missiles scenario would only include $10 \mathrm{MX}$ missiles anyway, after START II limits were reached, so elimination of that system would bo only a minor perturbation on that scenario. All 100 warheads on those MX missiles could be carried on single-warhead missiles instead. ${ }^{*}$ These could be Midgetman missiles, phased in as the MX missiles were eliminated, or possibly deMIRVed Minuteman III missiles, if the latter were still judged to be serviceable and if it were judged appropriate to increase the number of silo-based missiles. In the latter case, the Air Force might get the B-2 in fairly substantial numbers, to compensate it for the loss of the MX system. Another possibility would be to put these warheads on submarines and have a "Dyad" force structure. This scenario easily meets the postulated 800-SNDV limit, because there are fewer than 500 SNDVs in the maximum submarine-based missiles scenario under START II.

\footnotetext{
"Such a force could be reserved for limited options, instead of relying on slow bombers or on SIJBM: with all but one WH "dudded."
} 


\section{VERIFIABILITY}

Verification of START will be by national technical means (NTM), cooperative measures, on-site inspection (OSI), and on-site monitoring (OSM) (see Appendix ${ }^{32,38}$ ). . This section evaluates the verifiability of START II using START methods and identifies any potential verification problems. The main concern here is whether START verification methods will he adequate to ensure against the smaller violations that would be militarily significant under START II. It is unlikely that any treaty party would run the considerable pulitical risk of violating a treaty unless the advantage to be gained were perceived to be significiunt. This section also identifies what additional verification $R \& D$, if any, is needed and whit potential provisions or resulting force structures would make verification inherently difficult.

\subsection{DFLIVERY VEHICLES}

\subsubsection{Fixed ICBMs}

\subsubsection{Elimination}

Verification of the removal of fixed ICBMs from silos is not difficult. NTM would probably be sufficient; on-site inspection under START will provide certain verification of both removal of missiles from silos and destruction of the missiles themselves. Elimination of actual missiles was accomplished successfully under the intermediate-range nuclear force (INF) treaty. Thus, scenarios entailing elimination are easily verifiable.

\subsubsection{Counting of Deployed Missiles}

Using precedents set in START, it could be assumed for START II that any silo not shown to be empty by cooperative measures contained a missile. Missiles will also be subject to on-site inspection, and undeclared silos could be observed by NTM. Counting of deployed silo-based missiles is, therefore, straightforward under any scenario for START or START II.

\subsubsection{Nondeployed Missiles}

Nondeployed missiles could be of concern either if empty silos were loaded in violation of treaty restrictions, if silos were to be reloaded after an initial exchange, or if missiles were to be launched from nonhardened platforms (e.g., launch pads). Loading silos declared to be empty or placing missiles on launch pads could probably be detected by NTM before it significant number could be deployed and would not be expected to pose a real

\footnotetext{
*These verification measures are discussed in a previous Argonne report (Ref. 39).
} 
danger. Reloading during a war could be a potential concern. However, START includes provisions to inhibit rapid reloading of ICBM launchers.

"Hot-launching" of a missile from a silo renders the silo unusable, so reloading of silos holding hot-launched missiles is impossible. Therefore, storage of spare missiles noar sites where hot-launched missiles are deployed is not a major concern. Hot-launched missiles inclucle the Soviet SS-19 and the U.S. Minuteman.

Undamaged cold-launch silos could be reloaded in about a day, so reloads could conceivably contribute toward the tail end of an initial exchange. Nondeployed missiles at or near cold-launch sites could, therefore, be the subject of legitimate concern. Cold-launched fixed missiles include the Soviet SS-17 and SS-18 and the U.S. MX.

Silos would also become unusable if they were targeted during an initial exchange. The same is true of mobile missile bases, submarine bases, and airfields where SNDVs or their launchers/carriers could be reloaded. The likelihood of being targeted decreises the value of spare missiles at these sites.

Verification of spare missiles at deployment sites could be accomplished by a combination of initial on-site inspection followed by continuing observation using NTM.

\subsubsection{Mobile ICBMs}

\subsubsection{General Remarks}

Because it carries many warheads, a MIRVed fixed or mobile ICBM is militarily more significant than a single-warhead mobile missile. Therefore, the military signilicance of each clandestine single-warhead missile is lower, as is the necessity for exact counting. (However, deMIRVing would still need to be verified.) In addition, although expensive, production monitoring can ensure against future uncertainties in missile numbers. Since the United States has built no mobile missiles, the Soviets could be certain of the exact numbers we had in the future by monitoring production facility portals. (That number has now been decided as zero.) The more rapidly previously deployed systems lose reliability, due to cither physical degradation or uncertainty (because periodic testing is impossible), the less important are uncertainties in past production. Unfortunately, there is no reason to believe that covert systems will degrade rapidly. Information about the reliability of covert items of a legally deployed type can be obtained from testing the legal ones. Therefore, suspect-site inspection (SSI) at all sites where reasonable suspicions could arise should be included in START II to deter against covert deployment. Final START provisions dropped SSI, except at a small number of declared sites. 


\subsubsection{Road-Mobile Missiles}

Verification of the numbers of Soviet road-mobile missiles may not be easy. Mobile missiles moving around large deployment areas are by design very difficult to track. However, U.S. mobile missiles would probably have been rather easy to verify (and target), because only very restrictive basing modes would likely have been politically acceptable to the U.S. public. The Soviets could also face public pressure against large deployment areas. Counting missiles during cooperative displays or counting bases and attributing to them the number of launchers for which there are garages still leaves open the possibility of covert bases, it though these would be difficult to hide. Extra missiles entering declared bases could be detected by tagging and perimeter monitoring. If mobile missile tags cannot be authenticated, there is the possibility that more mobile missiles than those declared could be deployed at a base. This is a weakness in START that might be corrected in START II. Any number of covert mobile missiles left, under START would be doubly significant under START II.

Nondeclared missiles in covert storage would be very difficult to detect, although there would probably be some activity observable in connection with guards and necessary maintenance. This is more of a concern for mobile than for fixed missiles, because mobile missiles' launchers can travel as we:. The possibility of challenge inspections would increase the r'isk in holding nondeclared missiles.

Undamaged mobile launchers could be reloaded in a matter of hours after firing, so reloads could conceivably contribute toward the tail end of an initial exchange. (Soviet mobile missiles are cold-launched.) Nondeployed mobile missiles stored within easy traveling distance for mobile launchers could, therefore, be the subject of legitimate concern.

However, START limits on nondeployed mobile missiles will be verified by on-site inspection. Fairly large, visible equipment would be required for loading, and suspect-site inspections would have some chance of finding covert missile-loading sites. In addition, production monitoring can be used to verify the number of new mobile missiles produced. Previously hidden ones would be expected to become less reliable over time, because testing and maintenance would likely be detected.

\subsubsection{Rail-Mobile Missiles}

Counting trains for rail-mobile missiles might be somewhat easier than counting road-mobile missiles, because trains are more difficult to hide, assuming they are readily distinguishable from other trains. Verification of trains at rail garrisons can be done by NTM or OSI. However, there would still be the possibility of missile-carrying trains not equipped with the START-mandated visual signatures, either during a permitted dispersal or covertly deployed, roaming the vast Soviet rail network. This possibility would have been politically impossible in the United States, where the movement of missile-carrying trains would have been siverely restricted. 
Trains could only be loaded with covertly stored missiles at specialized stations with the requisite heavy equipment, and such facilities might be detectable.

\subsubsection{SLBMs}

Few ports are equipped to load nuclear submarines, and safety and logistics concerns make loading of additional missiles or warheads at sea essentially impossible without floating wharfs, which would be readily detectable by NTM. Therefore, submarines could be monitored in port, and subsequent loading and unloading could be witnessed after initial inspection. These measures would be sufficient even under the options of reduced vessel loading. These options are considerably more intrusive than those included in START, but they would provide assurance of submarine loadings. Further study would be required to determine if the benefits justified the costs.

Additional assurance that submarine tubes remained empty could be obtained by filling some of the missile tubes with concrete to render them inoperative. This is not necessary, however, and precludes options for deploying missiles with payloads other than weapons. Deployment of incompletely loaded submarines is an expensive option that the U.S. Navy would be expected to resist.

Submarines would need to get back to port if they were at sea when they fired their missiles (as U.S. submarines must be), but they could be reloaded faster if they were already in port (Soviet submarines can fire from port). Limitation of spare SLBMs near port facilities is, therefore, a possible concern; as with silo-based missiles, verification should be straightforward, and START does restrict location and movement of spares. In addition, there is a high probability that the ports would be destroyed in an initial exchange.

\subsubsection{Bombers}

Counting of actual bombers is straightforward because of their size and visibility. It should be possible to verify bomber numbers simply by counting, using NTM. Verifying bomber types may be slightly more difficult.

Under START, bombers that carry long-range nuclear-armed cruise missiles will have visible differences from, and be based at separate bases from, those that do not carry cruise missiles. Spare cruise missiles at bases could be limited and subject to inspection. However, they could only be used in a protracted war (one lasting for days). On-site inspection teams could make spot-checks to ensure that declared non-ALCM bombers of types that had been tested with ALCMs were not carrying covert ALCMs. This deception would not be expected to provide sufficient advantage to make it worth the risk. 


\subsection{NUCLEAR WARHEADS}

If START precedents apply under START II, counting rules will remove most. requirements for actually counting warheads. However, there are many arguments (not necessarily linked to START II goals) in favor of actually limiting the number of warheads, either deployed or total. These possibilities pose more stringent verification concerns.

\subsubsection{Deployed Missile Warheads}

START uses counting rules based on maximum (tested) missile loadings except for the limited number of downloaded systems; therefore, it does not require actual counting of all warheads on missiles. However, there is a provision for actual counting during on-site inspection to spot-check warhead declarations. Both U.S. and Soviet missile warheads have been counted already in cooperative test inspections.

Downloaded missiles would require verification of actual loading. If changes in missile loading are accomplished with the missile at least partially removed from its silo, this would he an observable event. Therefore, counting at initial downloading, supplemented perhaps by spot-checks and/or counting whenever the missile was removed and replaced for maintenance or other reasons, would be adequate to verify warhead numbers. A more stringent regime would be required if it were possible to covertly alter $R V$-loading of missiles in silos. A single inspection would be sufficient if the downloading process could be made irreversible. START requires replacement of the front section platform (and destruction of the old one) if an ICBM is downloaded by more than two RVs. This limits the threat of breakout. Whether warheads are counted visually or using radiation methods under START, the same method will be appropriate under START II.

The missiles to be loaded onto submarines could all be subjected to warhead counting in the same manner as ICBMs. START allows selection of one missile for inspection; additional inspections could be desirable under START II if SLBMs were declared as downloaded. In the cvent that either treaty party chose to deploy missiles with less than their maximum number of warheads, the possibility of adding additional warheads at sea could also arise. However, the logistics of handling a heavy explosive object in a cramped space with limited access to the RV bus make this possibility extremely remote. Therefore, counting in port should provide adequate verification of declared warhead loadings.

\subsubsection{Bomber Weapons}

\subsubsection{Deployed Bomber Weapons}

Bomber weapons are seriously discounted, leading to the so-called "bomber loophole" that allows significant numbers of legally deployed but uncounted warheads. The justification for this has been that bombers are slow fliers and not as much of a prompt stritegic threat, so that discounting was argued to be appropriate. Another justification is 
that bombers face air defenses, while missile defenses are limited. However, it could also be argued that having a significant number of extra warheads led to uncertainty and mistrust and was unnecessary, given the shrinking target base.

If the decision is made under START II to limit warheads actually deployed on bombers, some form of monitoring, possibly including counting, will be necessary. One. possibility is to declare the type of weapon carried and attribute to each bomber its maximum capacity. Mixed loads could be handled similarly. No inspection would then be necessary, except initially to verify the capacity of each type of aircraft. Verification of less-than-full loads would be difficult. While loading the bomber at its declared base could be observed, it would be difficult to prevent additional weapons from being loaded at another base, without extensive monitoring of bases. Therefore, counting rules based on partial loading could lead to undetected deployment of extra warheads (i.e., breakout).

The number of cruise missiles is not counted but is attributed with a counting rule up to a maximum number of bombers. The maximum number of actual ALCMs permitted is twice that nominal number. On-site inspections could be used to verify that this limit was adhered to, but the benefits of the additional ALCMs (if loading above the limits is even physically possible) may be too small to risk breaching a treaty. Further, neither party is likely to permit inspections that reveal the design of its rotary launchers. If either side deployed more ALCM carriers than allowed under the counting rule, the actual number of ALCMs deployed would need to be counted. The U.S. currently has more than 150 ALCM carriers, but the Air Force plans to eliminate enough of them so that counting will be unnecessary.

There is no provision under START for verification of ALCM characturistics. Conventional ALCMs, which are to be visibly different according to START from those declared to be nuclear, could be loaded with nuclear warheads for a potentially significant advantage if total numbers of nuclear ALCMs were limited under START II. Therefore, conventional ALCMs could either be sealed at production or be subject to spot-checks with radiation-detection equipment to ensure that they do not contain nuclear warheads. Alternatively, conventional ALCMs could be redesigned to make them incapable of holding: nuclear weapons. Another potentiai concern with ALCMs is their range. Only (nuclear) ALCMs with ranges over $600 \mathrm{~km}$ are to be limited under START. (iuidelines for determining ALCM range by physical characteristics (e.g., length or weight) easily observable during (nnsite inspection would be helpful for verification purposes. Should this prove difficult, it might be advantageous to limit all ALCMs under START II. (Note that the same concerns about characteristics would apply to SLCMs, if they were limited by START II and brought into the verification regime.)

\subsubsection{Nondeployed Bomber Weapons}

Bombers would require perhaps one half day to return to their bases after reluasing their loads on their presumed nonprompt missions, so they could be reloaded and rouserl in a matter of days after a first exchange (if the base survived). It is unlikely that ither 
appropriate planes would be available to load with strategic weapons. Stocks of bomber werpons are, therefore, of concern for the planning horizon that includes several days or more, but such stocks would not affect the relative strategic positions of both sides during an initial exchange.

Because bomber weapons are considerably smaller than ballistic missiles, covert. storage and transport is more feasible, making verification more problematic. However, nuclear weapons are likely to be stored in securely guarded sites and transported with visible protection, so there is some probability of detecting bomber weapon stocks.

\subsubsection{Nondeployed-Warhead Stockpile}

If START II were to limit the total number of nuclear warheads in U.S. and Soviot arsenals, verification would be a major undertaking, even compared with the extensive verification under START. It would be difficult and expensive; careful thought and study would be required to weigh the costs against the potential benefits. Verification of a limit on warheads would require cradle-to-grave tracking of weapons-grade materials to ensure against clandestine warhead production. Instituting such a system in the future (with or without a production cutoff) is relatively straightforward, although perhaps cumbersome. Imposing it retroactively and expecting to obtain sufficiently reliable information from the Soviet Union on which to entrust U.S. national security may not be possible.

Large numbers of warheads must be inventoried and accounted for, and production of wirheads must be monitored or halted. Similar measures for fissile materials would provide additional assurance against clandestine warhead production. These measures would be costly but possible.

The more difficult problem is to account for all past production and ensure against covert stocks of weapons that could eventually represent militarily significant quantities. Declaration and nuclear archaeology cannot be known to be complete and are, therefore, not sufficiently reliable. Additional cooperative measures could increase confidence; careful study would be required to determine if confidence were sufficiently high.

It would be difficult to obtain sufficiently convincing physical evidence that no significant stocks of undeclared weapons existed. The probability of deception might be low, but the potential consequences are sufficiently high to keep this as a real concern, even as our relationship with the Soviet Union improves. Information from intelligence sources cannot be expected to alleviate the concern, as was' shown by the discrepancies in missile production estimates revealed when INF data were exchanged. 


\section{IMPLICATIONS}

The major implications of the postulated follow-on to S'I'AR' concern three arous: the need for new weapon systems, the utility of possible START II provisions, and the necessity of continued warhead and fissile material production. 'There aro also sovoral arons where further work would be useful.

\subsection{THE NEED FOR NEW WEAPON SYSTEMS}

Timely completion of START II would reduce the need for deployment of new woapon systems. We distinguish between reductions in the numbers of weapons required and reduced need for new or modernized systems.

\subsubsection{Reduced Numbers of Weapons}

The total numbers of weapons required under START II could decrease for several reasons - fewer targets, decreased requirements for redundancy and damage expectuncy, requirements calculated on the basis of actual damage (including other factors besides blast overpressure), etc. Improved capability of weapon systems also reduces the number needed to do the same job.

The reductions under START and those furthei assumed under START' II will restrict the numbers of weapons permitted. Even if it were appropriate to replace ohsolete systems, the numbers built would be relatively modest. In addition, because START Il limits are proposed to be considerably lower than START limits, many of the weapons deployed under START would be eliminated under START II, Referring to START, Senator AI Gore (D)-Tenn.) remarked, "There is a real risk that we'll spend billions of dollars on wenpons wo'll wind up scrapping almost the moment they enter service." 40 The statement. would cortainly be true under START II. The force structure planned under START needs to be exilmined for the actual necessity of new weapons being planned or built now. If START II could he completed in a timely manner, or mutual unilateral reductions accepted, it might be possible to (xtend the service life of existing systems, rather than deploying something new just in time for cutbacks. If START II were seriously delayed, there would still be time in tho future to deploy additional weapons.

The target base appropriate for START II planning purposes will include fower Soviot weapons because of treaty-mandated reductions and will cover less area as the Soviet Union's area of domination shrinks. Therefore, even in the absence of careful culling of tho remaining targets, the numbers of weapons needed to cover the target base will be smallar. This implies the U.S. might be able to make do with (the modern components of') (xisting forces. 


\subsubsection{Fewer New Systems}

'The START treaty was very carefully written to permit modernization of strategic systems. A modernited system might be needed to replace an old system that no longer moets its requirements or is worn out, unreliable or unsafe, or expensive to repair, Modornization could also be required to meet more stringent performance requirements (e.g', harder targots, improved defenses, or a smaller CEP / circular error probablel to allow targeting with lower yield). Or a new system might offer an entirely new capability, liko stealth, that provides a significant advantage (at a reasonable cost). If additional weapon system:s were required, there could be advantages to using a new, superinr design,

Force modernization per se is neither good nor bad. Several types of goals can be achieved by modernization. Some of these are consistent with improving stability, and some we not. There is a need for selective modernization of our forces if doing so improves strategic stability and makes our forces or their command, communication, and control more survivable. Modernizing simply to improve capability is contrary to the goal of force recluctun. As John Steinbruner (Brookings Institution) said, "The weapons modernization programs are inconsistent with the logic of force reduction. You want to reduce forces to diminish the capacity of one side to attack the forces of the other. In the modemization progrimms, we're trying to enhance exactly that capability." 12

'The new systems being considered today can be evaluated from this perspective. The single-warhead Midgotman road-mobile missile would have been an acceptable element of the U.S. stritegic forces if it could have been based in a survivable mode (dash-on-warning is not su(ficient). Midgetman could be deployed in silos in small numbers for very limited options. However, its missions could be accomplished by other systems, either modern SLBMs or possibly single-warhead Minutemen. The D-5 is an existing, survivable system with the required promptness and accuracy, so the justification for Midgetman must rest on its being a hedge against an ASW breakthrough. Midgetman is also extremely expensivo per deployed warhead, compared to the J)-5 on fully loaded submarines. There does not appear to bo a pressing reason to build mobile Midgetman at this time, and the president has now terminated the program.

Similar arguments can be made for rail-mobile MXs. As currently based, the MX is dangerously destabilizing. A high priority should therefore be placed on moving it out of silos. The options were to put MX missiles on railroad cars, deMIRV them, or simply eliminate them from our strategic arsenal. Rail-basing was expensive (although rail-mobilo: MX was much less expensive than road-mobile Midgetman), and political constraints in the U.S. would have precluded wide dispersal, limiting the missiles' survivability. The president has also dropped this option. DeMIRVing is still possible, but it could imply a significant breakout potential. In the absence of a unique mission, elimination might be the best and most stubilizing option for the MX.

\footnotetext{
"This improved capability is only useful in the long run if it has no obvious counter. If it has a counterr, adoption would lead to an escalation spiral with no long-term benefit.
} 
The Trident/D-5 is survivable, has superior capabilities with respect to tho (i-1, and allows fewer deployed weapons for the same capabilities. If the U.S. and USSR agread (o) deMIRV SLBMs under S'TART II, or if the U.S. chose to load submarines with considerythly less than the maximurn numbers of missilos, the cost per SLBM warhend would riso, and the rolative economics would change, It might then be appropriate to considor small submarinos. However, SLBMs are survivable and likely to remain so for the furesecuble future, land they can be equipped for a variety of targeting missions. Submarine-based missilos can serve fior the U.S. the roles that land-based mobile missiles will probably serve for tho USSR. And while there is always much discussion of the possibility, significant advances in ASW are not projected over the life of the Trident and could probably be foreseen in time to develop countermeasures or alternative systems. Given the postulated S'I'ART II warhead limits, it would make sense to build the 18 Trident (Ohio class) submarines that the Navy is committed to for replacing aging and obsolete Poseidon submarines, but no more.

The other. new system in the works is the B-2 bomber, which uses elegint new technology. The B-2 bomber offers a clear improvement over previous aircraft: it cun (supposedly) avoid radar detection and pass through air defenses. But is the improvement necessary? The B-2 could take on penetrating, but not prompt, missions. These missions may generally be suitable for ALCMs, and restricting or targeting defenses would muko stealth unnecessary and allow any required penetrating missions to be assigned to $\mathrm{B}-1 \mathrm{Bs}$. So the advantages of the B-2 may be minimal. In addition, the B-2 may be too expensive to actually risk in conventional missions. For the time being, some of the existing B-52s could be kept in service, as SAC postulated in their post-START force mix. The need for large numbers of advanced bombers could be reevaluated when it became clearer what was to happen after START.

\subsection{THE UTILITY OF POSSIBLE TREATY PROVISIONS}

\subsubsection{Bomber Warhead Counting}

The current START counting rule, which accounts for all bumbs and SRAMis in a bomber as one warhead, leaves large numbers of deployed nuclear warheads uncounted (the "bomber loophole"), with no disincentive for adding more. The total number of warheads deployed under START will be significantly greater than the number accounted for, and this difference could represent an even larger fraction of deployed strategic warheads under START II if the same counting rules were applied. More realistic warhead accounting, either actually counting warheads or using counting rules that more closely approximated actual loadings, is likely under S'I'AR'T II and would provide more certainty about the actual status, thereby contributing to stability. Honest accounting would also be more in the spirit of real arms reductions.

There has been much discussion of the "bomber loophole," with advocates of " lie 13-2 bomber arguing that these extra warheads, which the B-2 could presumilly ciary on penetrating missions, are necessary to cover the extensive target hase. Even if correful 
examination of the target base after arms-control reductions and political restructuring were to leav' targets for the B-2, it must be asked in what situation the "extra" warheads would be employed. Presumably thiey would be used as part of a follow-on strike capability after a ballistic missile exchange destroyed first-priority targets. This is at best a marginal improvement in a situation that is already an unmitigated disast $r$. It would be more fruitful to concentrate on making such situations impossible. When asked "Would it be fair to say... that by the time the B- 2 is actually used, it would be after the virtual nuclear annihilation of both countries?", Air Force Chief-of-Staff General Welch replied, "I would think so." 1

A limit on the total number of deployed warheads could include separate sublimits on bomber warheads that reflected their lower perceived threat. Such a sublimit would be verifiatile if bomber warheads were accounted for using maximum loading. Another pussibility, which would probably be too intrusive and expensive, would be to witness actual loadingrs under noncrisis conditions and carefully monitor the storage of a severely limited number of spare warheads at bomber bases. Spot-checks, either as part of scheduled inspections or on challenge, could be made to count bombs on board.

\subsubsection{Total Warhead Limitation}

A ceiling on the total number of warheads in U.S. and Soviet arsenals would probably be very difficult to negotiate and even more difficult to verify, and the value of a ceiling ats part of a strategic arms treaty is unclear. In addition, warhead dismantlement is beginning unilaterally in the absence of treaty mandates, because the costs and risks of holding large numbers of warheads exceed the perceived benefits. President Bush has announced that the United States will begin dismantling tactical weapons, and President Gurbichev has followed his lead. ${ }^{1,3}$

\subsubsection{Deployed Ballistic-Missile Warhead Limitations}

The goal of these limitations is to restrict the most destabilizing systems. Currently agreed-upon START limits include a 4900 ceiling on deployed ballistic missile warheads and a sublimit of 1100 warheads deployed on land-based mobile missiles. In addition, the U.S. had proposed a sublimit of 3000-3300 on ICBM warheads, which the Soviet Union accepted coupled to a similar sublimit on SLBM warheads. The purpose and utility of the agreed limit on ali hallistic missile warheads are clear; the other sublimits are less obviously appropriate.

The sublimit of 3300 on ICBM warheads was greater than the number we had deployed, so it was of no consequence for the U.S. The Soviets would have needed to reduct the 1 . I' 'BM force considerably, but they could have accommodated such a limit. A similar' limit w SLBM warheads would have required that the Soviets retire some old submarines, but it would have introduced a major constraint on the. U.S., precluding highly submarinedependent force structures that would have been our most stabilizing options in the absence of mobul. missiies. It is, therefore, to our advantage that these sublimits were dropped. 
The utility of a sublimit of 1100 on mobile missile warheads, within the 4900 ballistic missile sublimit under START or the 2450 limit under START II, is also elusive. The ulvious reason for limiting mobile missiles is because the Soviets have them and we do not. Another pnssibility is that they are seen as targets that are difficult to deal with. Limiting mobile missiles does not, however, lead to enhanced stability or to fewer Soviet weapons, but unly to less survivable ones. The Soviet Union does not have the same access to warm-water ocean ports that makes submarines appropriate for the U.S. to deploy, so it looks to mobile land-based missiles as its major survivable strategic system. In addition, our political system would make effective dispersal of mobile missiles difficult, except perhaps in crisis, when the presirlent would be reluciant to disperse them for fear of sending the wrong message. So it is reasonable to permit the treaty parties an asymmetry in weapon systems.

From the standpoint of crisis stability, mobile missiles are a considerable improvement over fixed missiles. Limiting fixed missile warheads instead of mobiles would contribute more to the stability that is a major goal of START II. In particular, it would be desirable to eliminate the U.S. MX ("Peacekeeper") missile and the Soviet SS-18, both of" which are silo-based and carry $10 \mathrm{MIRVs}$ each. These are particularly obvious targets, especially for aficionados of the exchange ratio arguments, and therefore are likely to be launched on warning to avoid their loss. Their existence is thus very destabilizing. President Bush has recently announced our intentions to negotiate elimination of all land-based MIRVs.

\subsubsection{DeMIRVing}

The June 1990 summit statement included deMIRVing as a general goal for START II. However, the critical element, which might be what the presidents had in mind, would be to mandate deMIRVing of systems judged to be vulnerable. (The option of deMIRVing or downloading other systems would be available at the discretion of cach treaty party's force planners, within the limits set by START, although these options could leid to ('trification difficulties.) DeMIRVing is appropriate for fixed ICBMs. It would apply to submarines as well, if effective ASW were ever developed. Perhaps an appropriate gual at this puint would be to deMIRV fixed ICBMs (as President Bush wants) and let strategic planners allocate their remaining warheads on a treaty-limited number of SNDVs. Elimination of MIRVed systems or verification of irreversible deMIRVing (e.g., changing the bus) could make restrictions on downloading under START II unnecessary.

\subsubsection{Restricted Defenses}

Negotiating restrictions on systems designed to counter current weapons svstums might help to put a cay on a possible race to develop new systems of defensive weapons. The [i.S. need for the B-2 is in part justified by the claim that Soviet ail defenses will soun doily a penetrating mission to the B-1B. If verifiable limits on defenses cruld be negotiatrel and

\footnotetext{
'This is equivalent to elimination of fixed MIRVs if the Soviets keep their SS-24s in the rail grarrinus.
} 
verified cooperatively, both nations could save considerable expense with no loss of stability. One analyst has stated, "As long as the U.S. is dependent upon bombers and cruise missiles for deterrence, it seems inconsistent to reduce these forces without placing restrictions on Soviet air defenses." 42

\subsection{IMPLICATIONS FOR WARHEAD AND FISSILE-MATERIAL PRODUCTION}

Even under the most conservative treaty provisions, such as those already agreed upon for START, that merely limit the accounted number of deployed warheads, the number of strategic nuclear warheads needed by the U.S. is bounded. While the number we might decide to maintain is not determined by the treaty and will undoubtedly be subject to debate, we should not need more than the current stockpile under START. Follow-on treaties would further reduce our needs. The necessity for continued warhead production would then hinge on the porceived benefits of new designs and on difficulties in reusing warheads taken off of systems being reduced. Technical feasibility of reusing warheads in different, possibly: existing RV packages, should be examined. Careful study is also needed of the costs and potential benefits of marginal improvernents in warhead design. The mistrust and induced reciprocal activity generated by continued production might represent too great a price to pay: for any potential imp!ovement in war-fighting capability or greater perceived deterrent value to be achieved by better warheads. It is possible that the U.S. needs to build few, if any, additional warheads.

Even if warhead production were to continue, it is doubtful that much additional fissile material production would be required. Agreement to a cutoff of fissile material production would therefore not impose any additional constraints, beyond those caused by a oreed-upon warhead reductions, on U.S. defense programs. Many authors have provided careful analysis to document our sufficient stocks of heavy-element inputs to nuclear weipons. The only substantive question is the production of tritium. Tritium must be replenisht periodically because of its short half-life; however, significant reduction of warhead recuuirements under START II would unquestionably draw out current supplies and lead to mininal future tritium needs. Planning of new production facilities, therefore, could wait until car oful analysis, including the effects of future treaties, has determined the extent of the actual L.S. need.

\subsection{AREAS FOR FURTHER WORK}

\subsubsection{S'TART II}

This report has examined only U.S. force structures under START and START II. An equivalent study that developed force structures for the Soviet Union under the two treaties would provide insight into Soviet negotiating strategies for START II. In addition, this sturly has only looked at forces in a very general, aggregated way. A more detailed study should he undertaken, for both the U.S. and the USSR, to match forces with appropriate 
missions and target types in order to determine actual weapon and material requirements and to develop future force structures that minimize crisis instability.

Further study should also include implications of the full range of possible provisions that would increase stability under START II, including lower numerical limits as well as other types of provisions, such as limits on types of systems, restricted deployment modes, and revised alert procedures. Other options, such as modifications of START or informal agreements and unilateral reductions, should also be considered.

\subsubsection{Other Treaties}

As strategic arms levels are reduced, tactical and other weapons will take on added importance, and we should consider the possible utility of agreements limiting these weapons as well, if unilateral reductions are insufficient. Although arms control has, to date, been accomplished by separate treaties for each weapon class, it is necessary to examine the potential interrelationships among treaties, especially as deeper reductions in strategic arms are sought. It is also important to answer several questions. How do a production cutoff, dismantlement, and testing limitations fit in with treaties limiting weapon systems? What is the best way to carry out arms reductions in a rapidly changing world? Are formally negotiated treaties too slow, or are they still useful to prevent backsliding? Consideration of these and similar questions would help direct arms-control research to the most fruitful areas. 


\section{REFERENCES}

1. N'w York Times, national ed, quoting President Bush on reducing U.S. and Sovict. nuclear weapons, p. 3 (Sept. 28, 1991).

2. Norris, R., and T. Cochran, Making a Virtue of Necessity: ST.1RT and Strategic: Modernization, Nuclear Weapons Databook Working Paper 90-1, National Resources Defense Council, Washington, D.C. (May 15, 1990).

3. New York Times, national ed., quoting President Gorbachev on nuclear arms cuts, p. 11 (Oct. 6, 1991).

4. Joint Stutement on Future Negotiations on Nuclear and Space Arms and Further Enhancing Strategic Stability, reprinted in Arms Control Today, 20(5):23 (June 1990).

5. Scuwcroft, B., et al., Report of the President's Commission on Strategic Forces, p. 29, ( $\left.\Lambda_{\text {pril }} 6,1983\right)$.

6. Deutch, J.M., The Decision to Modernize U.S. Intercontinental Ballistic Missiles, Science, 24.1:1445 (June 28, 1989).

7. Marsh, G., Future Deterrence: The Role of Military Power in a Unified World Economy, U.S. Department of Defense, Office of the Chief of Naval Operations (June 1990).

8. New York Times, national ed., excerpts from Pentagon briefing, quoting U.S. Secretary of Defense Cheney, p. 3 (Sept. 29, 1991).

9. Ball, D., and R. Toth, Revising the SIOP, International Security, 14(4):65-92 (Spring 1990).

10. General David Jones: Redefining Security, Expanding Arms Control, interview in Arms Control Today, 20(8):3 (Oct. 1990).

11. Kortunov, S., START II and Beyond, Bulletin of the Atomic S'cientists, 46(8):21 (Oct. 1990).

12. Budiansky, S., What's a Bomb for, Anyway, U.S. News and World Report, p. 25 (March 19, 1990).

13. Davis, R.C., "Potential START II Outcomes and their Implications," prepared by Science Applications International, McLean, Va., for Los Alamos National Laboratory (Sept. 14, $1990)$.

14. Van Voorst, B., America's Doomsday Machine, Time, p. 19 (July 16, 1990).

15). Schmemann, S., "Gorhachev Matches U.S. on Nuclear Cuts and Goes Further on Strategic Warheads," New York Times, national ed., p. 1 (Oct. 6, 1991). 
16. Adams, P., Pentagon Considers Arms Control Plan: Soviet Mobile SS-24 for U.S. Mobilc. MX, Defense News, p. 33 (March 26, 1990).

17. Nitze, P., Address to the Institute for Foreign Policy Studies, Defense Daily, p. 390) (March 13, 1990).

18. Smith, R.J., "Cheney Orders U.S. A-Missiles, Bombers Taken Off 'Alert'," Washington. Post. p. 1 (Sept. 29, 1991).

19. Pre-Summit Slowdown: Complexities Catch up with START, CFE, Arms Control Today, 20(4):13 (May 1990).

20. Bunn, M., SS-18 Modernization: The Satan and START, Arms Control Today, 20(6):13 (July/Aug. 1990).

21. Strategic Arms Reduction Talks, Arms Control Reporter, Brookline, Mass., p. 611.B.615 (March 1990).

22. Washington Post, quoting President Gorbachev's letter to President Bush, p. A10 (April 9, 1990).

23. Convention on the Prohibition of the Development, Production and Stockpiling of Bacteriological (Biological) and Toxin Weapons and Their Destruction, in Arms Control and Disarmament Agreements, U.S. Arms Control and Disarmament Agency (1982).

24. "Executive Summary," in Report to Congress: Verification of Nuclear Warliead. Dismantlement and Special Nuclear Controls, U.S. Department of Energy Report DOE 3151 (July 1991).

25. Lockwood, D., Congressional Budget Action: B-2 Cuts and SDI Limits, Arms Control Today, 20(7):18 (Sept. 1990).

26. Ruiz Palmer, D.A., START II and Other Nuclear States, Workshop on Potential STAR'T II Outcomes and their Implications, Science Applications International, McLean, Va. (Sept. 27, 1990).

27. "Bush's Bold Arms Plan," Financial Times, London, p. 18 (Sept. 30, 1991).

28. Kaplan, F., "U.S. eyes cuts in nuclear warheads," Boston Globe, p. 1 (July 4, 1990).

29. Toth, R., "Proposed Arms Pact Launches Strategy Debate," Los Angeles Times (July 25, 1989).

30. Toth, R., "Planners Split on How to Meet Nuclear Threat," Los Angeles Times (July 24, 1989).

31. Sloss, L., Reexamining Nuclear Policy in a Changing World, Center for National Security Studies, Los Alamos National Laboratory Report LA-11998, No. 11 (Dec. 1990). 
32. The Strategic Arms Reduction Treaty: The START Data Base, U.S. Arms Control and Disarmament Agency Fact Sheet, Washington, D.C. (Aug. 1, 1991).

33. Cochran, T.B., et al., U.S. Nuclear Forces and Capabilities, Nuclear Weapons Databook, Vol, I, Ballinger (1984).

34. Kent, G., and D. Thaler, "First-Strike Stability," RAND Corp. (1990).

35. Nitze, P., "Bush's Moves Reduce Risk of Nuclear War," Los Angeles Times, p. B5 (Oct. 3, 1991).

36. Marsh, G., and L. Gaines, letter to the editor, Science, 246:193 (Oct. 13, 1989).

37. Bumn, M., SAC Force Proposal: 11,700 Warheads under START?, Arms Control Today, 20(1):31 (Feb. 1990).

38. The Strategic Arms Reduction Treaty: Basic Provisions of the Treaty, U.S. Arms Control and Disarmament Agency Issues Brief, Washington, D.C. (July 29, 1991).

39. Gaines, L., et al., Accommodation of On-Site Inspection at DOE Facilities, Argonne National Laboratory Report ANL/ACTV-88/2 (Oct. 1988).

40. Evans, D., "Weapons builders vs. the arithmetic of arms control," Washington Post (July 13, 1990).

41. Dellums, R., "A Service in Search of a Bomber," Washington Post, p. 25 (July 26, 1989).

42. Speed, R.D., Strategic Forces: Future Requirements and Options, Center for Technical Studies on Security, Energy, and Arms Control, Lawrence Livermore National Laboratory Report CTS-07-90 (UCRL-ID-105336) (Nov. 1900). 
APPENDIX:

START PROVISIONS*

${ }^{*}$ Reproduced from Refs. 32 and 38. 


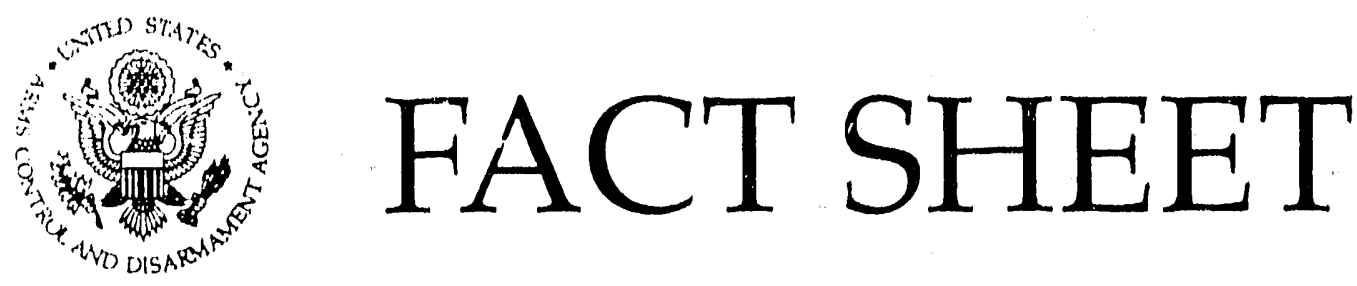

\section{THE STRATEGIC ARMS REDUCTION TREATY \\ August 1, 1991 \\ START Data Base}

The Mernorandum of Understanding (MOU) on Data contained in the START Treaty establlshes a benchmark data base and categories of Treaty Limited ltems (TLI) for the Treaty. This facliltales verification of compliance with Treaty obligations. The data contained in the MOU are accurate as of Se stember 1, 1990. An update to the data will be exchanged 30 days after the Treaty enters into force, and baseline inspections will be conducted to help verify the data. The chart betow contains those US and Soviet strategic nuclear de livery vehicles (SNDVs) and their warheads, which are subject to the central limits. The second charts illustrates how central limits will affect current forces.

US FORCES

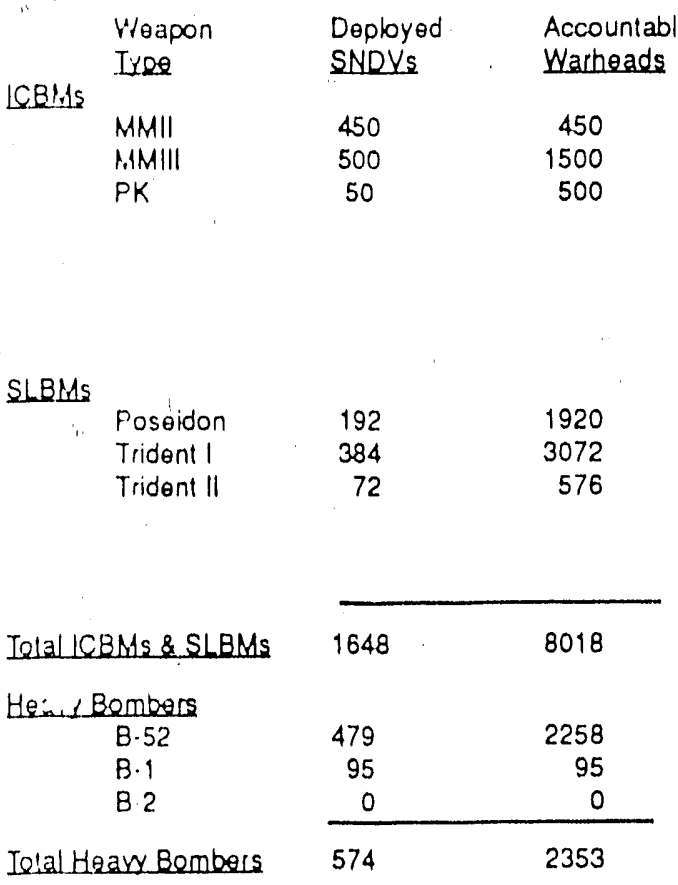

\section{SOVIET FORCES}

$\begin{array}{lcc}\begin{array}{l}\text { Weapon } \\ \text { Iype }\end{array} & \begin{array}{c}\text { Deployed } \\ \text { SNDVS }\end{array} & \begin{array}{c}\text { Accountable } \\ \text { Warheads }\end{array} \\ \text { SS.11 } & 326 & 326 \\ \text { SS-13 } & 40 & 40 \\ \text { SS.17 } & 47 & 188 \\ \text { SS-18 } & 308 & 3080 \\ \text { SS.19 } & 300 & 1800 \\ \text { SS.24 (silo) } & 56 & 560 \\ \text { SS.24,(mobile) } & 33 & 330 \\ \text { SS.25 } & 288 & 288 \\ \text { SS.N-6 } & 192 & 192 \\ \text { SS.N-8 } & 280 & 280 \\ \text { SS.N-17 } & 12 & 12 \\ \text { SS.N.18 } & 224 & 672 . \\ \text { SS.N-20 } & 120 & 1200 \\ \text { SS.N-23 } & 112 & 448 \\ & 2338 & 9416\end{array}$

Bear Blackjack

\begin{tabular}{rl}
147 & 735 \\
15 & 120 \\
\hline 162 & $85 ! 5$
\end{tabular}

-assumes attrit ution of 3 wartearta in aciordance with EFFECT OF START REDUCTENS ON CURRENT FORCES downlnaairig provisions

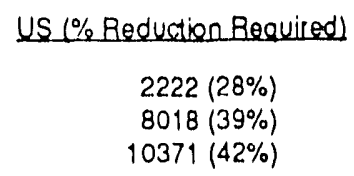

Soviet $1 \%$ Reduction required)

$2500(36 \%)$

$9416(48 \%)$

$10271(41 \%)$

$3080(50 \%)$ 


\section{ISSUES BRIEF}

July 29, 1991

\section{THE STRATEGIC ARMS REDUCTION TREATY}

\section{Basic Provisions of the Treaty}

\section{START REDUCTIONS}

- Reductions to equal aggregate levels in strategic offenslve arms, carried out in three phases over seven years from the date the treaty enters into force.

- Speciflc, equal interim levels for agreed categorles of strategic offensive arms by the end of each phase.

- Central limits include:

1,600 Strategic Nuclear Delivery Vehicles (SNDVs)

- 6,000 accountable warheads

- 4,900 ballistic missile warheads

- 1,540 warheads on 154 heavy intercontinental ballistic missiles (ICBMS) for the Soviet side. The Soviets also agreed in a side letter to eliminate 22 SS-18 launchers every year for seven years to achieve this level.

- 1,100 warheads on deployed mobile ICBMs

- Throw-weight ceiling of 3,600 metric tons

\section{DELIVERY VEHICLES}

- 1,600 ceiling on the number of SNDVs, comprising deployed ICBMs and their associated launchers, deployed submarine-launched ballistic missiles (SLBMS) and their associated launchers, and deployed heavy bombers.

\section{WARHEADS}

- 6,000 accountable warhead celling, comprising the number of warheads attributed to deployed ICBMs and SLBMs, the number of long-range, nuclear-armed air-launched cruise missiles (LRNA) attributed to heavy bombers equipped for LRNA (see LRNA), and one warhead attributed to each heavy bomber equipped only for nuclear-armed gravity bombs and short-range attack missiles (SRAMs). 


\section{BALLISTIC MISSILE WARHEADS}

- Each ballistic missile warhead attributed to a missile counts as one under the 6,000 warhead ceiling.

- No lilght testlng of missiles with RVs in excess of attributicd number.

- A quota of on-site inspectlons to verlify that deployed ballistlo misslles contain no more RVs than the number of warheads attrlbuted to them.

- Ban on new types of ICBMs and SLBMS with more than 10 warheads.

- Ban on increasing warhead attribution on future types of ICBMs and SLBMs.

\section{DOWNLOADING}

- The number of warheads on up to three existing types of ballistic missiles and thelr altribution under START may be reduced ("downloaded") up to a tolal of 1,250 RVs.

- Each Soviet SS-N-18 may be attributed with 3 RVs; a total of 896 SS-N-18 warheads count toward downloading limit.

- US Minuteman III may be reduced by 1 or 2 RVs.

- Insofar as permitted by the 1,250 limit, up to 500 RVs may be downloaded on two other existing ballistlo misslle types (up to 4 RVs per missile).

- Ban on downloading of new types. Ban on deploying a new type with more warheads than on a downloaded type (except for the Minuteman III and the SS-N-18). Ban on downloading of heavy ICBMs.

- If an ICBM is downloaded by more than Iwo RVs, it must be equipped with a new front section platform, and all old platforms destroyed.

\section{HEAVY ICBMS}

- In addition to the requirement to reduce deployed heavy ICBMs and their warheads by 50 percent, other constraints on heavy missiles include: no downloading; no increase in launch weight or throw-weight; no mobile launchers for heavy ICBMs; ban on new types of heavy missiles. New heavy ICBM silo construction allowed, but only in exceptional cases for relocation or to replace eliminated heavy ICBM silos in extraordinary circumstances; never to exceed 154 such silos. Modernization and testing of existing heavy ICBM's can continue. 


\section{NEW TYPES OF ICBMS AND SLBMS}

- An ICBM or SLBM will be considered a new lype of ICBM or SLBM if it meets any of the following crlterla: change In number of stagos; change In typo of propollant; 10 percont change in missile or first stage length: 10 percont ohange In mlssile launch weight; 5 porcent change In dlameter; 5 percent change in first stage length comblined with 21 percont increase in throw.welght.

- Celling of 21 percent on permitted increases to throw.weight ol existing types of ICBMs or SLBMs.

- Warhead attribution for future types of ICBMS and SLBMs w'll be the maximum number of RVs tested and simulated, but no less than the number derlved by dividing 40 percent of mlsslle throw-weight by welyhil of the lightest RV tested on that type of ICBM or SLBM. Applicatlon of the 40 percent rule to new systoms with unconventional front ends will be dlscussed at the $\mathrm{JClC}$.

\section{HEAVY BOMBERS}

- Each heavy bomber counts as one SNDV. Fach heavy bomber equipped only for nuclear weapons other than long-range nuclear alr-launched crulse missiles (l.e., only for gravity bombs and SRAMs), counts as one warhead under the 6,000 lim/t. An agie日d number of heavy bombers could be removed from accountability under the 1,600 SNDV limit by conversion to a non-nuclear capabillty. Heavy bombers equipped for long-range nuclear ALCMS (LRNA), will be distinguishable from other heavy bombers.

- In exchange for not including the Tupolev 22.M (Backflre) bornber in START, the Soviet Unlon will make a politlcally-binding declaration that it will not deploy more than 300 air force and 200 naval Backfires and that these bombers will not be given intercontinental capability.

\section{LONG RANGE NUCLEAR AIR-LAUNCHED CRUISE MISSILES (LRNA)}

- Nuclear-armed ALCMs with a range in excess of 600 kllometers (LRNA) will be affecled under START. New long range conventlonally-armed ALCMs that are distingulshable from nuclear-armed ALCMs are nut limited in START and may be deployed on any aircraft.

- For the purpose of counting against the 6,000 warhead limit, accountable warheads will be attributed to heavy bombers equipped for LRNA as follows: each current and future US heavy bomber equipped for LRNA will count as 10 warheads (except as noted below) but may aclually be equipped for up to 20 LRNA. Each current and luture Soviet heavy bomber equipped for LRNA will count as 8 warheads (except as noted below) but may actually be equipped for up 1016 LRNA.

The United States may apply the above counting rule to 150 heavy bombers equipped for LRNA; the Soviet Union may apply the above counting rule to 180 heavy bombers equipped for LRNA. For any heavy bormbers equipped for LRNA in excess of these levels, the number of attributable warheads will be the number of LRNA for which the bombers are actually equipped.

- Multiple-warhead long-range nuclear ALCMs are banned. 


\section{MOBILE ICBMS}

- Categories of permitted movements and associated notifications live been agreed.

- Non-deployed mobile ICBMs and launchers will be limited numerically and geographically (SEe NON-DEPLOYED MISSILES belOW).

- Soviet mobiles are: SS.24 and SS-25. For purposes of reciprocity the US Peacekeeper will be treated a, mobile although it has never been tested as a mobile ICBM.

\section{NON-DEPLOYED MISSILES}

- There will be a numerical limit of 250 on non-deployed ballistic missiles for all ICBMs of a type that has been flight tested from a mobile launcher; of those, no more than 125 may be non-deployed missiles fur rail-mobile launchers. There also will be a numerical limit of 110 on non-deployed launchers for mobiles of which no more than 18 may be non-deployed lauchers for rail-mobile ICBMs.

- Other non-deployed ballistic missiles will not be subject to numerical limits, but there will be restrictions on their location and movement and they will be subject to data exchange requirements.

- Various provisions are also agreed to inhibit rapid reload of ICBM launchers.

- The sides have also agreed there will be no restrictions on the number of cruise missiles and other heavy bomber weapons. There will be limited restrictions on the location of LRNA.

\section{EXEMPTIONS FROM TREATY LIMITS}

- 75 non-modern heavy tombers equipped for non-nuclear arms, former heavy bomjers, and training heavy bombers.

- 20 test heavy jombers.

- 25 test silo launchers and 20 test mobile launchers at test ranges.

\section{SLCMS}

- Sea-launched cruise missiles (SLCMS) will not be constrained in the START Treaty. However, each side will provide the other with a politically-binding declaration concerning tong-range nuclear SLCMS, i.e., those nuclear SLCMs whose range is over 600 kilometers in annual declarations, the planned maximum number of these deployed nuclear SLCMs for each of the following five Treaty years will be specifiec. The planned niaximum number will : texceed 880 long-range nuclear SLCMS. Nuclear-armed SLCMS with a range of 300-600 kilometers will be the subject of confidential annual data exchanges. The sides will not produce or deploy multiple warhead nucleer SLCMS. 


\section{VERIFICATION}

The Strategic Arms Reduction Treaty (START) was designed with verification in mind, and verification measures were negotiated in parallel with other aspects. Thus, the basic structure of the Treaty is designed to facilitate verification by national technical means (NTTM). The START Treaty contains detailed, interlocking and mutually reinforcing provisions, which supplement national technical means to establish an effective verification regime. This regime provides for data exchanges and notifications on strategic systems and facilities covered by the Treaty, a ban on the denial of data from telemetry, twelve types of on-site inspection and exhibitions, continuous monitoring at mobile ICBM final assembly facilities, and cooperative measures. These elements are outlined below.

- NATIONAL TECHNICAL MEANS (NTM) - START provides for the use of, and noninterference with, national technical means of verification, e.g. satellites. There are explicit provisions prohibiting interference with NTM, or use of concealment measures that impede verification by NTM.

- TELEMETRY - Pa.ties are prohibited from engaging in any practice that denies full access to telemetric information during missile flight tests, with certain limited exceptions. Moreover, Parties are obligated to exchange telemetry tapes, interpretative data and acceleration profiles for every test flight.

- DATA EXCHANGE AND NOTIFICATIONS - Prior to Treaty signature, the sides will exchange data on numbers, locations, and the technical characteristics of START. accountable weapons systems and facilities and will provide regular notifications and data updates thereafter.

- COOPERATIVE MEASURES - Seven times a year, either party may request the other to display in the open road-mobile launchers, rail mobile launchers and heavy bombers at bases specified by the inspecting fialty. Additional cooperative measures may be requesited following an operational dispersal.

- CONTIN.JOUS MONITORING AOTIVITIES - START establishes continuous monitoring at the perimeter and portals of each sirie's mobile ICBM assembly facilities. The US has the right to establish a monitoring facilin' at Votkinsk, which is the final assembly racility for the SS-25, and at Pavlograd, which is the final assembly facility for the SS-24. The Soviet side has the right to monitor the Thiokel Strategic Operations facility at Promontory, Utah, the final assembly facility for the accountable stage of the Peacekeeper. Such monitoring would also be established at any future facilities at which mobile ICBM assembly takes place.

- ON-SITE INSPECTIONS (OSI) - There are twelve types of OSI and exhibitions. These are: haseline data inspections, data update inspections, new facility inspections, suspec: site inspections, reentry vehicle inspections, post-exercise dispersal inspections, conversi in or elimination irspections, close-out inspections, formerly declared facility inspections, technical characteristics exhibítions, distinguishability exhibitions and heavy bomber baseline exhibitions.

- COMPLIANCE - Compliance concerns may be raised by either side in the Joint Complia"ice and inspection Commission (JCIC) or any other appropriate forum 


\section{DATA DENIAL}

- Agreement to broadcast ali telemetric information from test flights of ICBMs and SLBMs and to ban any practice (including encryption, encapsulation and jamming) that denies full access to telemetric information, with certain limited exceptions.

- Requirement to provide full telemetry tapes, acceleration profiles, and certain specified interpreti:information after each test flight of an ICBM or SLBM.

- As a goodwill gesture, the sides agreed not to engage in encryption or jamming beginning 120 days after Treaty signature.

\section{TREATY DURATION}

- Treaty will have a duration of 15 years, unless superseded earlier by a subsequent agreement.

- If the sides agree, treaty may be extended ior successive five year periods.

\section{NON-CIRCUMVENTIONTTHIRD COUNTRY ISSUES}

- No transfer of strategic offensive arms (SCA) to third countries, except that there will be no interference with existing patterns of cooperation, e.g., American cooperation with the United Kingdom.

- There will be no permanent basing of SOA outside national territory and no inspections outside national territory. Temporary stationing of heavy bombers overseas permitted, but certain notifications may apply. Port calls for SSBNs permitted. 


\section{DISTRIBUTION FOR ANL/ACTV-91/7}

\section{Internal}

ANL Contract Copy

K.S. Macal (6)

ANL Patent Department

L. Gaines (125)

ANL Technical Publications Services (3)

\section{External}

U.S. Department of Energy Office of Scientific and Technical Information (12) Manager, U.S. Department of Energy Chicago Operations Office ANL Libraries (2) 

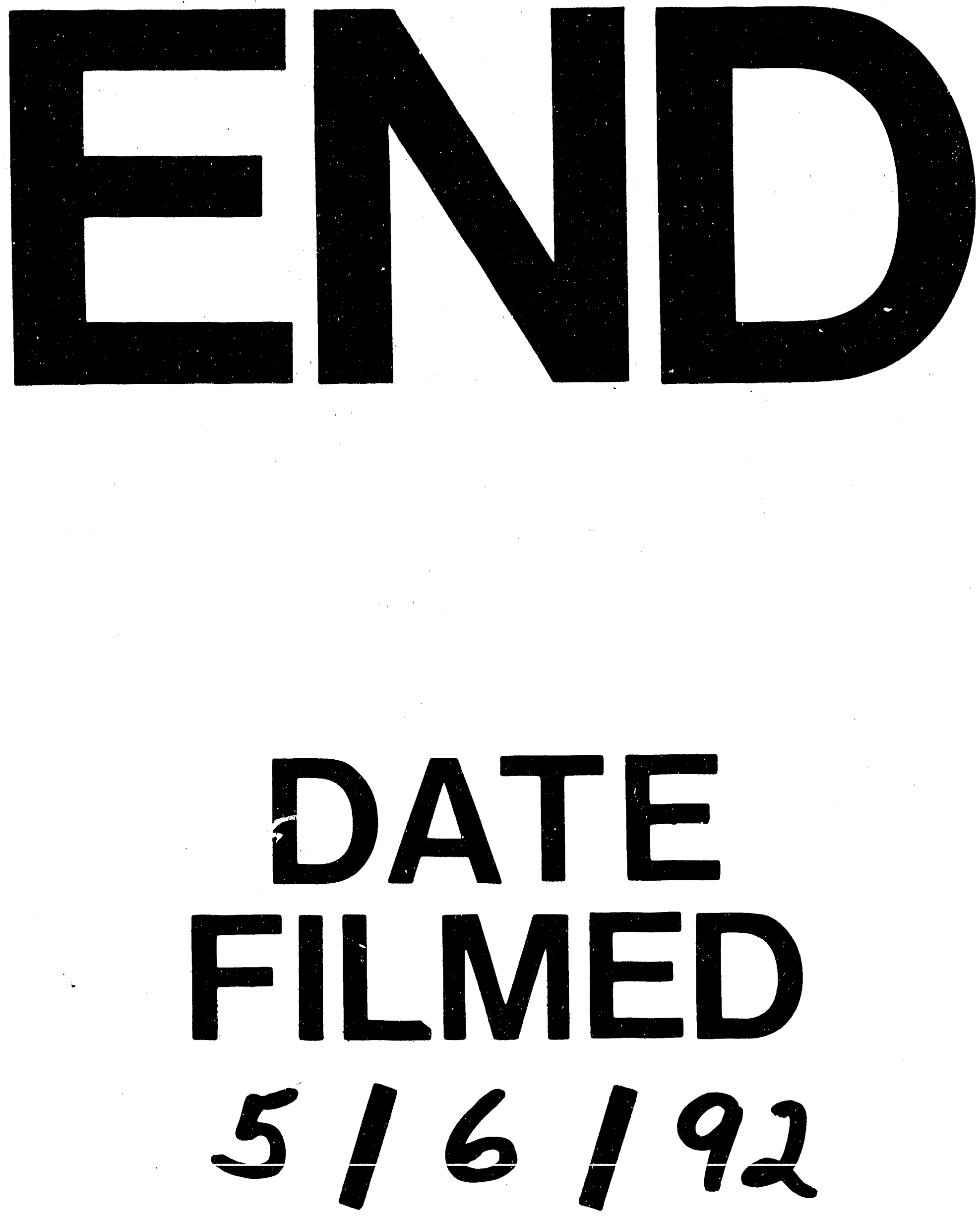
